\title{
Curtailing Anthropogenic Carbon Dioxide to Meet the Targets of the Paris Agreement using Technology Support Mechanisms
}

\author{
Nitin Agarwala ${ }^{*}$ and Semion Polinov ${ }^{2}$ \\ ${ }^{1}$ National Maritime Foundation, New Delhi, India \\ ${ }^{2}$ Maritime Policy \& Strategy Research Center, University of Haifa, Israel \\ ${ }^{1}$ nitindu@yahoo.com, ${ }^{2}$ semion.polinov@gmail.com
}

\begin{abstract}
Increasing the contribution of carbon dioxide emissions due to anthropogenic factors has been a subject of discussion for many years now. One of the positive outcomes of these discussions was the Paris Agreement that aims to limit the global average temperature rise between $1.5^{\circ} \mathrm{C}$ to $2.0^{\circ} \mathrm{C}$ over preindustrial levels. To achieve this target, countries were required to self-manage their GHG emissions to limit the global average temperature rise to $2.0^{\circ} \mathrm{C}$ by 2030 and then slowly transition to zero-emission by 2050 to eventually achieve $1.5^{\circ} \mathrm{C}$ of global average temperature rise. However, over the last two decades, the efforts to achieve the targets of the Paris Agreement have had mixed success, thereby making the set targets a dream and forcing the world community to rethink if the set goals are realistic and achievable. Recent studies of carbon dioxide emitted during the first quarter of 2020 due to forced confinement as a result of COVID-19 have shown a reduction by nearly 17 percent, thereby, re-kindling the belief that the targets of the Paris Agreement are achievable. It is with this motivation that the article reviews how and why carbon dioxide concentration has been increasing over the years and how anthropogenic contributions are affecting the delicate balance of the air quality that is leading to accelerated climate change. Also, the paper discusses the technological imperatives proposed by IPCC to address the increasing anthropogenic carbon dioxide emissions and the technology support mechanisms required for achieving the Paris Agreement targets.
\end{abstract}

Keywords: Anthropogenic carbon dioxide, Climate change, Energy; GHG emission, Natural carbon dioxide, Support mechanism, Technology, Transportation

\section{Introduction}

The Earth's temperature has been continuously changing since the formation of planet Earth [Figure 1]. This temperature of the Earth, in general, is dependent on how much energy is received from the Sun and how much of it is radiated back into space. While the energy from the Sun is more or less constant, the radiated energy depends significantly on the chemical composition of the atmosphere. As a natural process, of the total energy received from the Sun, nearly 30 percent is reflected from light-colored surfaces such as clouds, ice, snow, and deserts while the remaining is absorbed by the Earth. This thus helps the Earth to achieve a temperature of $-18^{\circ} \mathrm{C}$, as against an observed average temperature of $15^{\circ} \mathrm{C}$, thereby creating an unexplained temperature anomaly. It was only in 1827 that Fourier solved this unexplained temperature anomaly by proposing that the atmosphere is responsible to keep the Earth warm by absorbing

Article history:

Received (February 2, 2021), Review Result (March 9, 2021), Accepted (April 9, 2021) 
outgoing infrared radiation and then radiating them back such that the Earth's surface gets part of the radiated energy while the remaining is lost to space [1]. It was only in 1861 that Tyndall showed the working mechanism of this hypothesis [2]. He showed that water vapor, carbon dioxide $\left(\mathrm{CO}_{2}\right)$, methane $\left(\mathrm{CH}_{4}\right)$, and nitrous oxide $\left(\mathrm{N}_{2} \mathrm{O}\right)$, are the gases that cause this radiation to create atmospheric greenhouse heating, a phenomenon called - the greenhouse effect. He also indicated that a small change in concentration of these gases introduces a strong influence on the Earth's temperature and hence climate in the long run. These changes that occur in the climate (which is the statistical average of the weather as a result of the Earth's temperature taken over a long period, typically 30 years), have been sometimes gradual while at others abrupt.

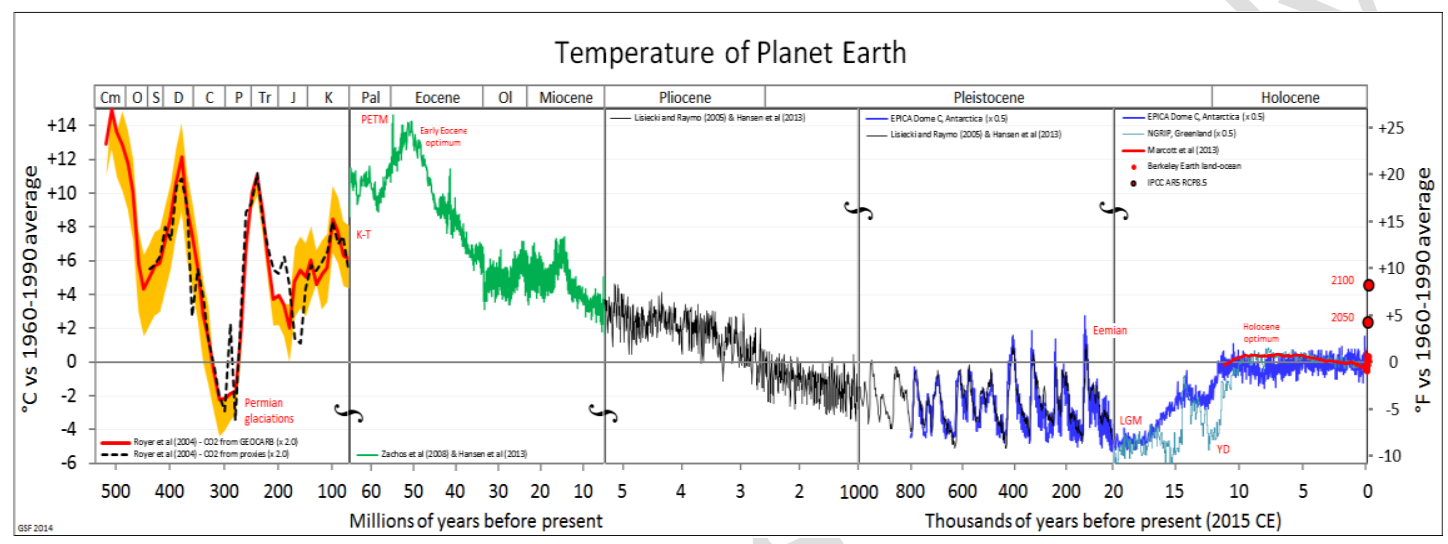

Figure 1. Earth's temperature over the years [3]

Of the four gases, 'water vapor' does not influence the climate, but merely responds to the changes by other gases and amplifies them. The contribution to the greenhouse effect of the other three gases, even though $\mathrm{CO}_{2}$ makes up only 0.036 percent of the atmosphere, $\mathrm{N}_{2} \mathrm{O}$ 0.00003 percent and $\mathrm{CH}_{4} 0.00017$ percent [4], is large, which allows the Earth to maintain a life-comfortable $15^{\circ} \mathrm{C}$ temperature on Earth.

This thus brings us to several important questions. If this natural cycle, called the 'Energy Budget', is being adhered to naturally and is ensuring liveable conditions on Earth, then what and where is the problem? Why is it that the drastic effects of climate change are being observed? What has changed that humanity is worried sick? What is so critical about 'climate change' that an independent international organization - 'The Intergovernmental Panel for Climate Change (IPCC)' - has been formed and nearly all the countries meet regularly basis to discuss the issue of climate change?

Over the years, most of these questions have been discussed in great detail and various forms and forums [5][6][7][8][9]. The understanding from these discussions and studies that emerge and that is universally accepted is that the concentration of the three gases viz. $\mathrm{CO}_{2}, \mathrm{~N}_{2} \mathrm{O}$, and $\mathrm{CH}_{4}$ are being altered by anthropogenic (human) efforts. As indicated by Tyndall, minor changes in the concentration of these gases have a major effect on the climate of Earth [2]. Hence, anthropogenic causes of altering the concentration of these three gases are causing changes in the climate that has far more ramifications than acceptable to humanity.

The question that one needs to answer is, if all this has been discussed and accepted, then what is it that this article would discuss which is different from the earlier efforts! At the outset, let us confess that the motivation of this article is an article by Le Quéré et al. [10] in Nature 
Climate Change and another similar one by Liu, et al. [11] in Nature Communications that have pointed out that a temporary reduction in the annual global $\mathrm{CO} 2$ emissions has been observed during the forced confinement due to COVID-19 during 2020 as a result of reduced energy and transportation demands as seen in [Figure 2]. This thus gives us hope that all is not lost and with some dedicated efforts, climate change can be slowed down if not reversed.

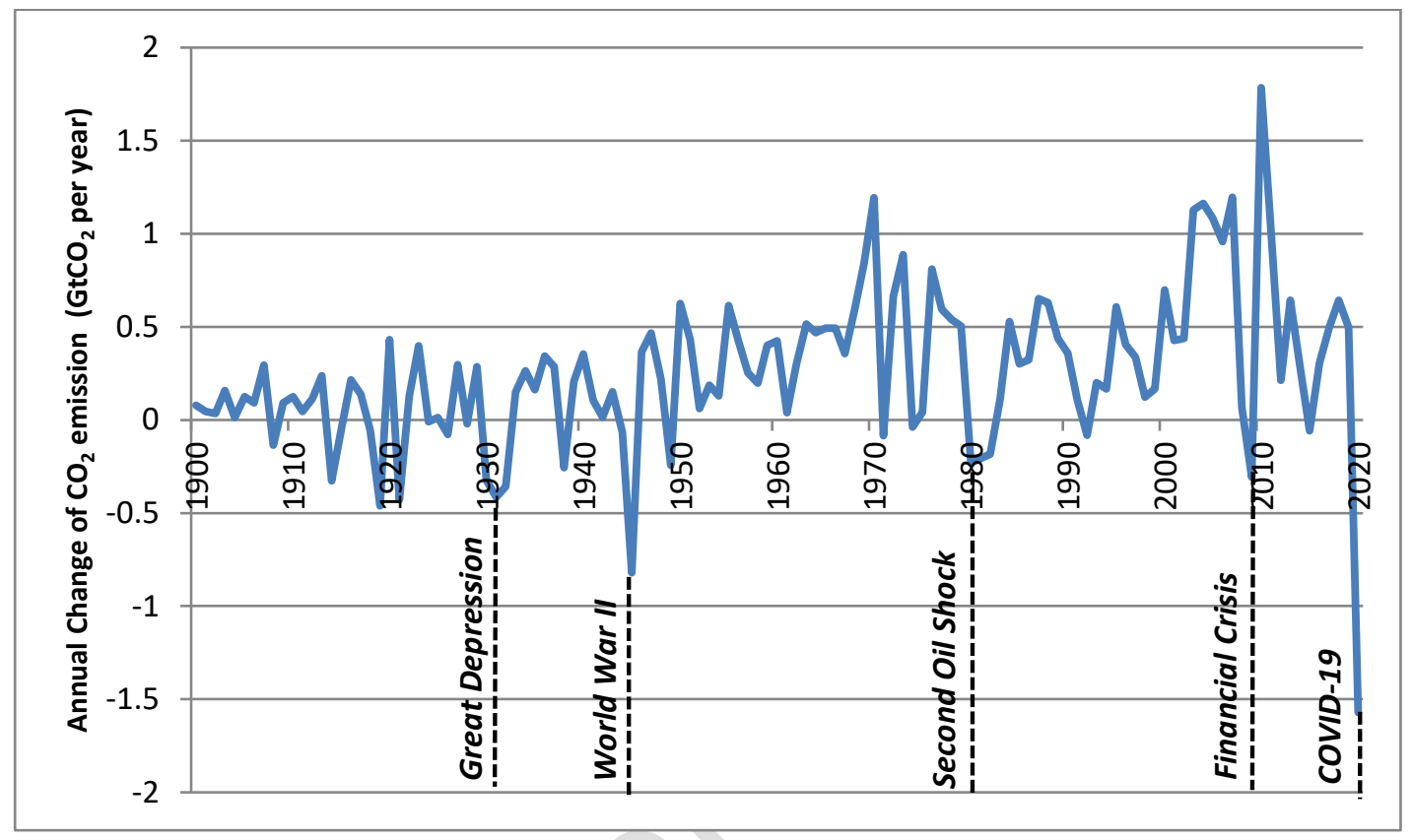

Figure 2. Annual change of $\mathrm{CO}_{2}$ emissions since 1990, adapted after [11]

It is with this motivation that the article reviews how and why carbon dioxide concentration has been increasing over the years and how anthropogenic contributions are affecting the delicate balance of the air quality that is leading to accelerated climate change. Also, the paper discusses the technological imperatives proposed by IPCC to address the increasing anthropogenic carbon dioxide emissions and the technology support mechanisms required for achieving the Paris Agreement targets.

\section{Why is this review required?}

As the number of active cases of the novel coronavirus (COVID-19) increased across nations, its transmission got linked to human mobility. This necessitated the curtailment of human mobility as a basic minimum, thereby shutting down the borders and confining humanity to their respective living spaces in a state of curfew never seen or imagined by most in their living memory. The lockdown (forced confinement) to follow brought about both economic and noneconomic human activities to a stand-still. Activities such as travel, construction, industrial and commercial, that were considered so far, an essential part of life could no more be pursued. Automatically, the environmental damage these activities were causing began to reduce. This brought about clearer skies and cleaner water bodies that in return led to reduced levels of air and noise pollution, allowing birds, animals, and aquatic beings to show their presence once again. 
While the world was in a state of forced confinement and out of business, it was a once-ina-lifetime opportunity for environmental scientists to study the impact of the anthropogenic contribution of $\mathrm{CO}_{2}$ emission. Of the numerous studies undertaken on various aspects, those undertaken by Le Quéré et al., [10] and Liu, et al., [11] have shown that anthropogenic factors have a very important role to play in the climate change occurring on planet Earth. These studies have also shown that if the human element is removed from the environmental changes that occur naturally, as was seen during the recently forced confinement, the Earth has the requisite capacity to heal itself. While it is difficult to predict the future, two future scenarios are possible. One, wherein an effective vaccine is developed and the second, wherein humanity learns to live with the virus by altering their lifestyle as they have with other viral diseases such as flu, smallpox, yellow fever, AIDS, polio, Ebola, Zika virus, and SARS-1. The question that arises is - how will the resulting scenario change human activities at the regional, national, and international levels?

It is interesting to note that while the forced confinement may have been detrimental for one particular industry (like the airline industry) it has been good for some other industry (like the shipping industry). It is ironic that though forced confinement has been considered a negative feature for human independence and economic growth, it has helped bring back the positives of clear skies and blue waters and their vibrant life back to them. While the human-led technological developments cannot be stopped and neither can the forced confinement and restrictions on human activities remain forever, economies will bounce back to their lost glory sooner or later. However, even if an effective vaccine is developed, what looks most likely in the near future is that there would be a lesser physical movement of people and a greater reliance on technology for communication. It thus becomes essential for nations and organizations to make the right decisions towards investments and the reopening of businesses and the times to follow to save our planet from the catastrophe called 'climate change'.

It thus becomes important to ensure that humanity at various levels is convinced about the looming danger of climate change and shows the much-needed concern for the environment. However, since the impact of climate change is not uniform across the globe and within a region itself, such enlightenment has its limitations and hence the ways of coping at different places must be different. This notwithstanding, COVID-19 has brought human life to a near grinding halt, forcing everyone to pause and see the damage human activities are doing and how this pause has helped the environment to heal itself without anthropogenic contribution.

While the issue of climate change has been discussed for many decades now, such a live example of nature's healing of this magnitude has never been seen before. It is hence important that a review of where humanity stands and what the future holds for them is put forth to the world to rekindle their concern and thinking. After all, if the right decisions are not made now while the economies and businesses are reopened, it may be too late. It thus becomes imperative to address this issue, as soon as possible, for the world leaders to review future steps of recovery to make them sustainable rather than the old business-as-usual model steps.

To rekindle this thinking, the article first explains global warming by looking at the cause of increasing global temperatures, the natural Carbon Cycle, the available $\mathrm{CO}_{2}$ budget, and the natural contributors to anthropogenic $\mathrm{CO}_{2}$. In the next section, various methods to resolve climate change through technological imperatives to address $\mathrm{CO}_{2}$ emissions and using COVID19 as an initiator will be discussed. This would be followed by understanding if humanity is on track and recommending some feasible support mechanisms to assist in a possible success to control climate change before concluding the article.

While we discuss these steps, it is essential to appreciate that a delayed action or inaction by the world leaders in the interest of economics, will slowly edge the planet towards a certain 
extinction sooner than what we have envisaged. This is based on an understanding that Nature has its ways of resetting the ills of humanity by pushing human beings out of the working equation itself, as seen during the present episode of forced confinement. It is important to mention that the intention is not to make prophecies, but to forewarn of the impending dangers that are looming large (extreme weathers, floods, droughts, earthquakes, etc.) but are being overlooked in the interest of economics and development without realizing that both economics and development have little meaning if the very existence of humanity cannot be sustained.

\section{Understanding global warming}

Studies on global warming indicate that the factors contributing to climate change are both natural and anthropogenic. Natural events such as the changing intensity of the Sun, ${ }^{2}$ natural systems such as forest fires, oceans, wetlands, permafrost, mud volcanoes, earthquakes, volcanic eruptions, ${ }^{3}$ and changes in naturally occurring greenhouse gas concentrations of $\mathrm{CO}_{2},{ }^{4}$ $\mathrm{CH}_{4},{ }^{5}$ and $\mathrm{N}_{2} \mathrm{O}^{6}$ are some naturally occurring contributors to climate change. However, the influence of these natural events is way too small to be of any serious consequence [12] when compared with the influence of anthropogenic events. That effectively leaves the anthropogenic events as the primary reason for the rapidly occurring climate change. This belief is supported by studies undertaken using climate models with global temperatures measured in the last 150 years [13]. Scientists note that they can fit the observations only till 1950 without including the increase in greenhouse gases. This effectively means that the contribution of greenhouse gases (GHG) in the increase in the global temperature of the Earth is an important contributor. Since GHG has been continuously increasing, it necessitates the inclusion of these contributors in all further analyses [12]. This said it is necessary to remind that the climate changes seen on Earth since the Precambrian time (4.6 billion - 542 million years ago) have been purely due to natural events. However, in recent times, these slow-acting, naturally occurring events have been overshadowed by the anthropogenic contribution of GHG emissions that have displayed relatively fast results such as the melting of the polar ice cap, glaciers, and sea ice, and shifting of precipitation patterns to name a few.

\subsection{Cause of increasing global temperatures}

Studies have shown that the global atmospheric concentration of these gases has increased substantially in the last hundred years [14]. Of these gases, $\mathrm{CO}_{2}$ has seen the steepest rise from an annual average of $280 \mathrm{ppm}$ in the late $1700 \mathrm{~s}$ to $407 \mathrm{ppm}$ in 2018 [14][15] due to the increased usage of fossil fuels with an annual increase of $2.64 \pm 0.08 \mathrm{ppm}$ [16] as seen in [Figure 3]. Similarly, the $\mathrm{CH}_{4}$ concentration has more than doubled to reach approximately $1,800 \mathrm{ppb}$ in 2017 due to agricultural use and fossil fuel usage with an annual increase of $10.4 \pm 0.6 \mathrm{ppb}$ [16] as seen in [Figure 4], and that of $\mathrm{N}_{2} \mathrm{O}$ has increased from $280 \mathrm{ppb}$ to nearly $329 \mathrm{ppb}$ in 2016

\footnotetext{
${ }^{2}$ Happens every 11 years when the magnetic field completely flips over and can cause fluctuations in global temperatures by up to 0.2 degrees.

${ }^{3}$ On average, volcanoes emit between 130 and 230 million tonnes of carbon dioxide per year, while burning fossil fuels releases about 26 billion tonnes of carbon dioxide every year (as of 2005).

${ }^{4}$ Largely result from natural processes like respiration. Geologic (rocks, soil) and hydrologic (water) processes and cycles affect both the emission and uptake of carbon dioxide from Earth's environments.

${ }^{5}$ Methane is released in low oxygen environments such as swamps and bogs and through the roots of some plants, termites, oceans, sediments, volcanoes, and wildfires.

${ }^{6}$ Nitrous oxide is produced by microbial (bacterial) processes in soil and water. The use of fertilizers with nitrogen and some industrial processes also contribute to atmospheric $\mathrm{N}_{2} \mathrm{O}$.
} 
due to agricultural activities as seen in [Figure 5]. It can be seen that the combined effect of these anthropogenic GHG emissions is increasing steadily [Figure 6].

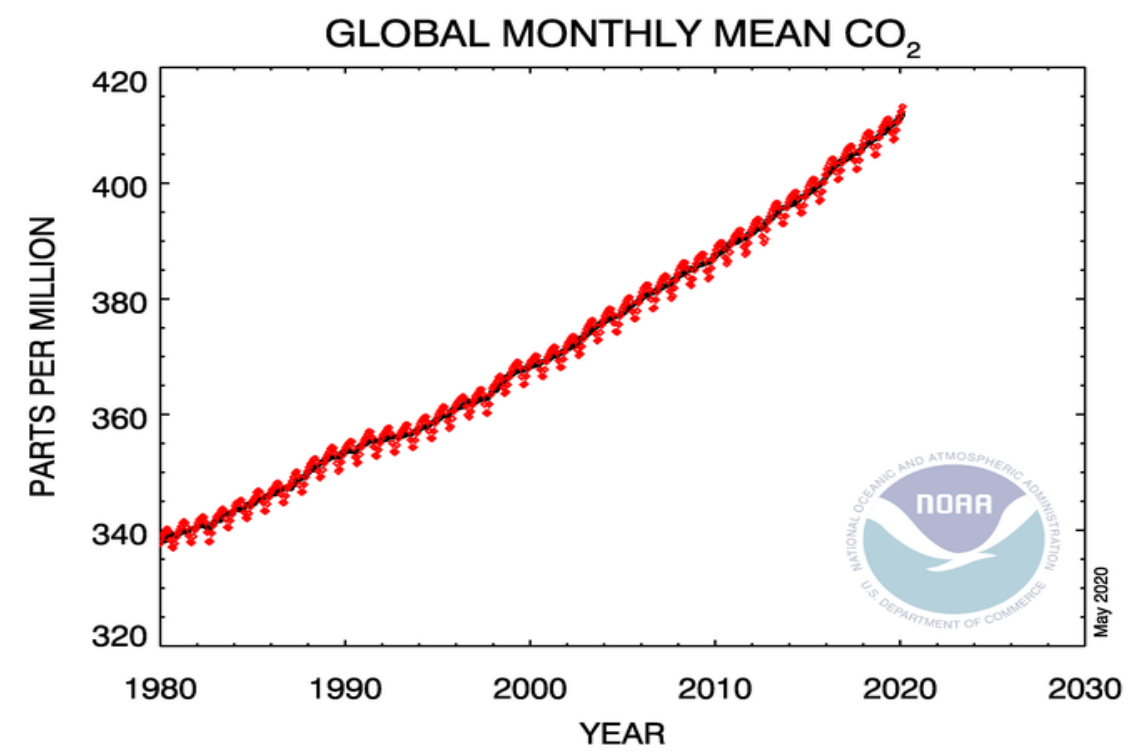

Figure 3. Increase of $\mathrm{CO}_{2}$ in the atmosphere over time [17]

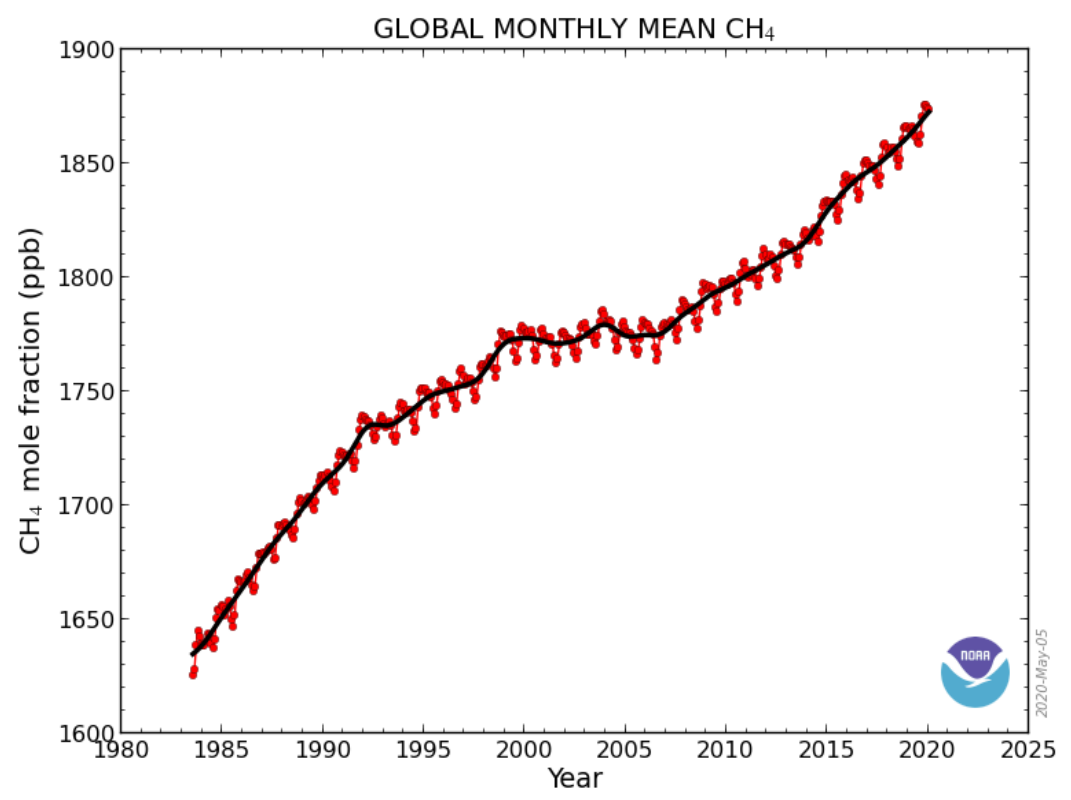

Figure 4. Increase of $\mathrm{CH}_{4}$ in the atmosphere over time [18] 


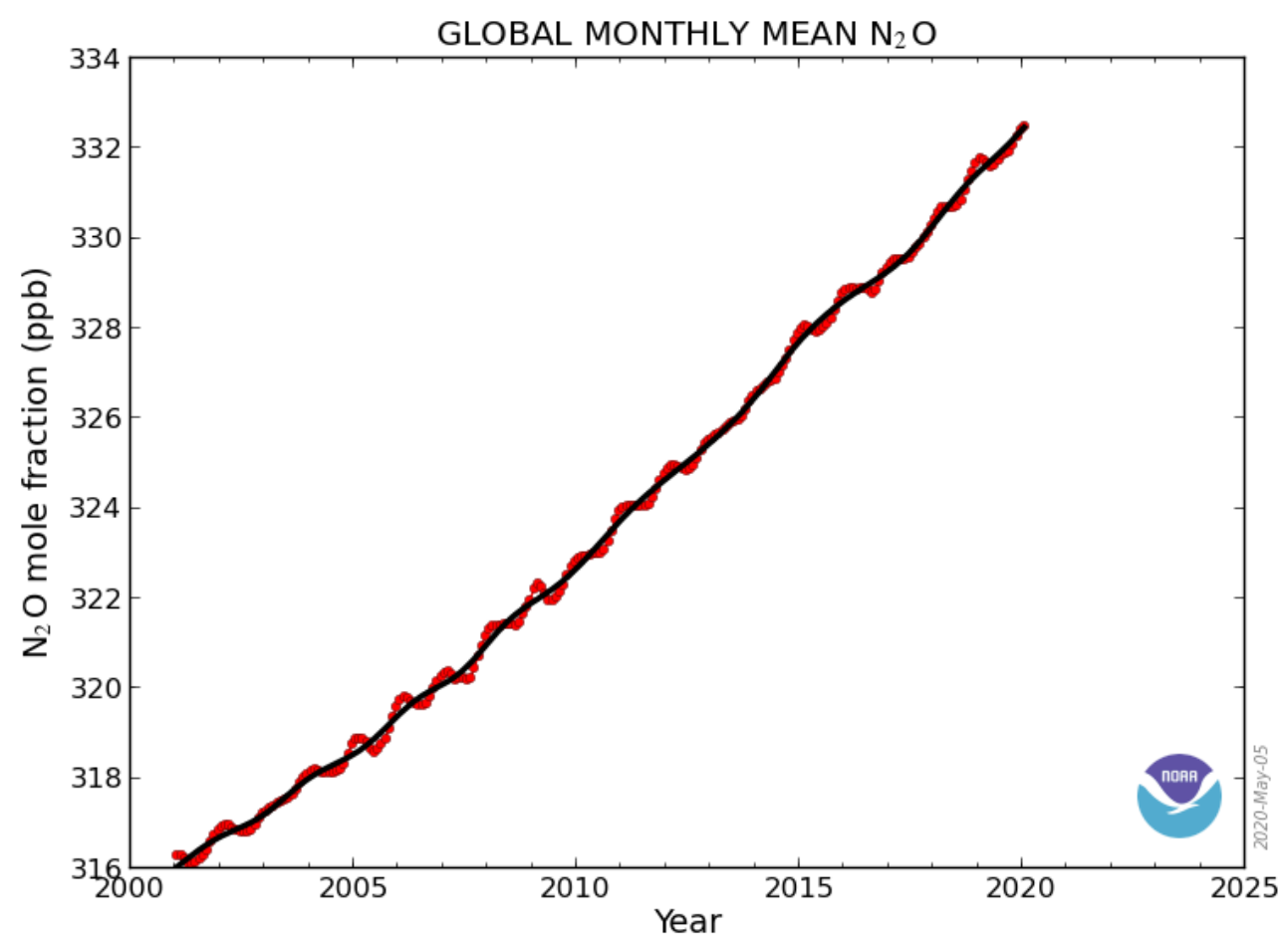

Figure 5. Increase of $\mathrm{N}_{2} \mathrm{O}$ in the atmosphere over time [19]

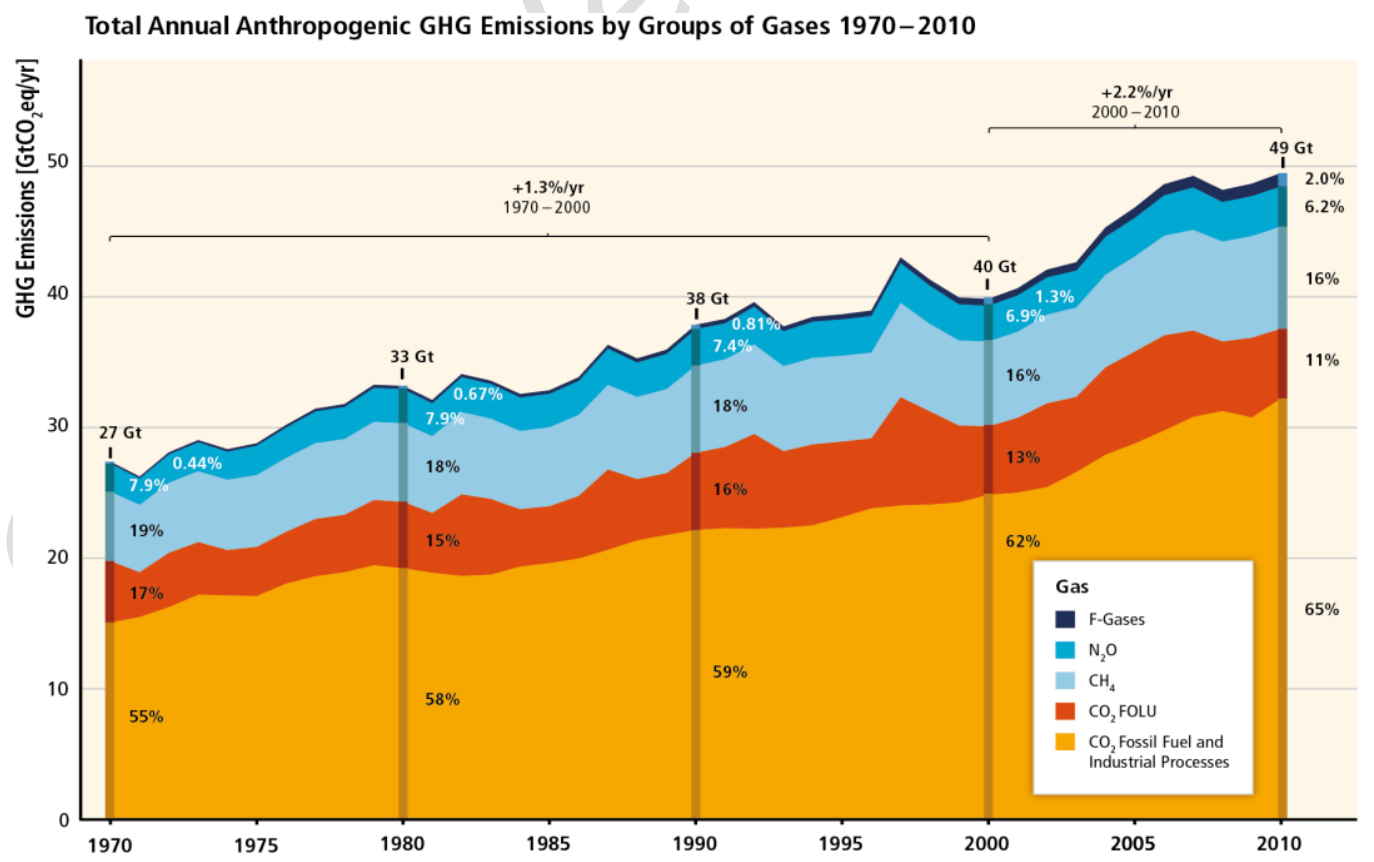

Figure 6. Anthropogenic GHG emissions [20] 


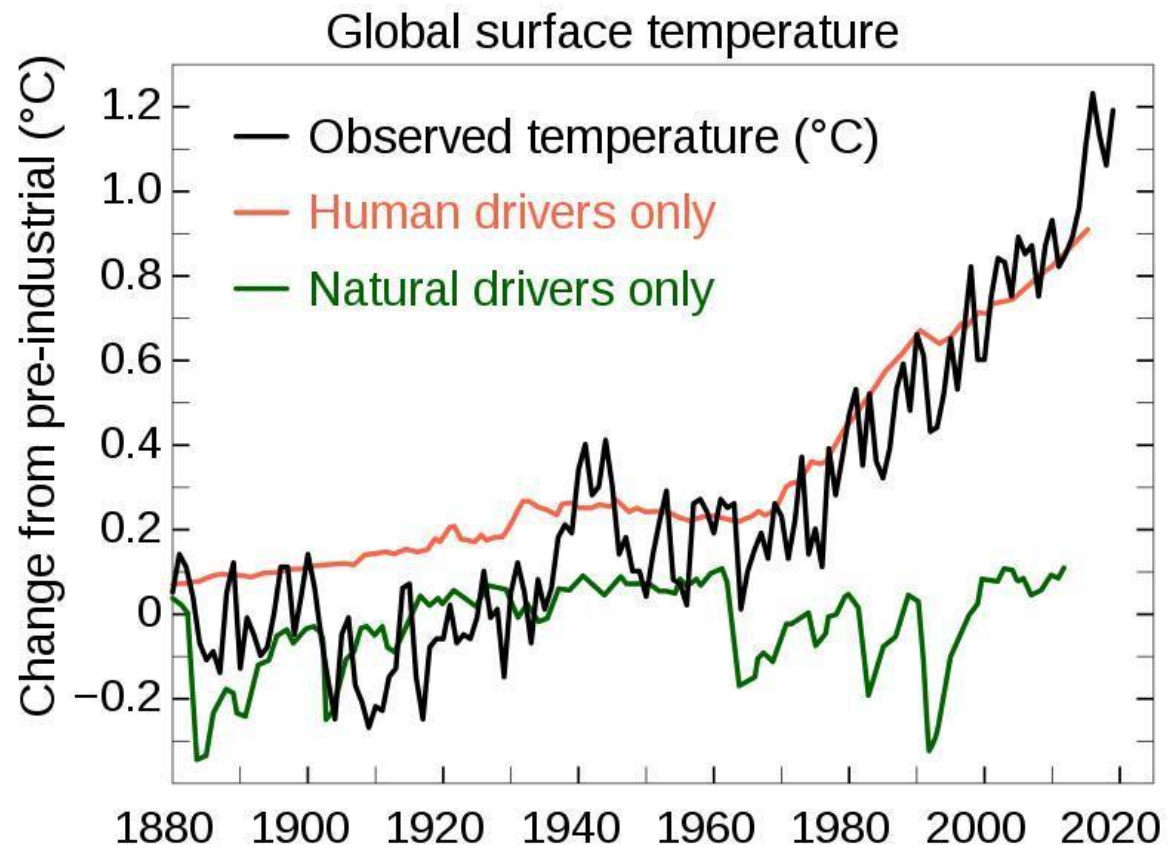

Figure 7. Global surface temperature [21]

It is important to note in [Figure 6] that while the total anthropogenic contribution of GHG continues to grow year on year since 1970, the relative contribution of the constituents is also increasing proportionately. Of the contributing emissions, $\mathrm{CO}_{2}$ is the major contributor at 76 percent of the total GHG emissions of which 65 percent is due to fossil fuels and industrial processes and 11 percent is due to emissions from various land use and forests. The next largest contributor is methane $\left(\mathrm{CH}_{4}\right)$ from agriculture activities, biomass burning, waste management, and energy use at 16 percent, followed by nitrous oxide $\left(\mathrm{N}_{2} \mathrm{O}\right)$ that is used in fertilizers at 6 percent, and the Fluorinated gases used in industrial processes and refrigerants contributing the remaining 2 percent. These increases are contributing to the increase of the global temperatures of the Earth while the contribution from natural drivers has remained nearly stable as seen in [Figure 7].

The point to be noted is that while the natural system is self-balancing, the additional contribution due to an anthropogenic system is exerting more pressure on the Earth's energy budget thereby unbalancing the system. It is furthermore essential to understand that $\mathrm{CO}_{2}$ tends to stay in the atmosphere for thousands of years by being sequestered in layers of the Earth where they never existed before and does not absorb energy in excess. $\mathrm{CH}_{4}$ on the other hand is nearly 21 times more effective than $\mathrm{CO}_{2}$ in radiation absorption, but it stays in the atmosphere for only ten years [14]. Similarly, $\mathrm{N}_{2} \mathrm{O}$ survives for nearly 120 years before it is removed from the atmosphere. Such a survival life of these gases causes the effect of the anthropogenic system to have a longer-lasting effect. Accordingly, the result of any reduction in the GHG emission will be visible only after a long time, by when possibly it will be too late for humanity.

Also, one observes that this increased GHG emission has resulted in the average global temperature of the Earth to increase by a little more than $1^{\circ} \mathrm{C}\left(2^{\circ} \mathrm{F}\right)$ since 1880 with two-thirds of this warming happening since 1975 , at a rate of roughly $0.15-0.20^{\circ} \mathrm{C}$ per decade [22]. It is imperative to mention that the impact of global warming is not limited to the increase in global temperatures alone. Such temperature increase tends to modify rainfall patterns causing 
droughts and floods, causes a rise in sea level, coastal erosion, increases the growing season of crops, causes heat waves resulting in melting of ice caps and glaciers, and supports the spread of several infectious diseases. The global temperature rise is hence a matter of serious concern that needs the world's attention more than war footing.

\subsection{Natural carbon cycle}

Having understood that $\mathrm{CO}_{2}$ is the major contributor to the increase of the global temperature of the Earth, let us understand how this carbon flows naturally in various forms. To understand this cycle, it is imperative to understand that carbon in nature resides in rocks, the ocean, the atmosphere, plants, soil, and fossil fuels as reservoirs. The carbon present naturally flows between these reservoirs. Any event that removes the carbon from these reservoirs and adds it to the atmosphere causes an increase in the Earth's global temperature. Nature has its mechanism to remove this carbon from the atmosphere by using rain, photosynthesis, and absorption by the oceans to name a few. Before the Industrial Revolution, the ocean released $\mathrm{CO}_{2}$ into the atmosphere to balance the carbon it received from the rocks due to weathering. However, as carbon concentrations increased in the atmosphere, the ocean is now only absorbing carbon from the atmosphere, becoming acidic and losing its ability to absorb more $\mathrm{CO}_{2}$ from the atmosphere.

\subsection{The $\mathrm{CO}_{2}$ budgets}

Since the natural carbon cycle has been disturbed, the Earth is warming rapidly. Accordingly, it was agreed upon in the Paris Agreement (2015) that the Earth cannot be allowed to increase its temperature by more than $1.5^{\circ} \mathrm{C}$ from the pre-industrial ${ }^{7}$ levels. This is based on an understanding that if the levels are permitted to breach the $1.5^{\circ} \mathrm{C}$ marks, most of the changes would become irreversible. Hence, organizations such as the IPCC and the IEA, defined a carbon budget for the world to ensure that the Earth as a system does not heat more than this pre-accepted magical figure of $1.5^{\circ} \mathrm{C}$ from the pre-industrial levels. This idea of a 'carbon budget' is based on a strong relationship between cumulative emissions and temperatures. It links future warming to the total amount of $\mathrm{CO}_{2}$ emissions. Though the concept began as a simple tool, over the years, it has become quite complicated due to the different models used that provide very different results. Some of the accepted models for estimating the carbon budget include the ESM (Earth System Model), IAM (Integrated Assessment Model), and the GCM (General Circulation Model). Like a house budget, the carbon budget aims to provide a limit of $\mathrm{CO}_{2}$ that can be released into the atmosphere in the forthcoming years. For calculating this budget, carbon emission from fossil fuels and industries is used. While there are various means of getting this data, the one provided by the United Nations Framework Convention on Climate Change (UNFCC) is considered the most accurate and reliable [23]. However, it is important to understand that many activities such as shipping and aviation occur outside the nation's territory thereby creating errors. Similarly, varying carbon and heat content of fuel creates another set of errors, making the calculation process complicated and incorrect.

Though the intention of understanding the available $\mathrm{CO}_{2}$ through the carbon budget is considered critical to better appreciate the impact of climate change, however, the carbon budget as defined by IPCC and IEA varies due to differences in the definition of the pre-

\footnotetext{
${ }^{7}$ The baseline when the scientists assume that the effect of human-induced climate change was theoretically zero. This has been selected as the period 1850-1900 by the IPCC since the global record-keeping of climate change began then.
} 
industrial date, the range of temperature probability, the climate sensitivity, ${ }^{8}$ the inclusion of the anthropogenic efforts, the inclusion of the GHG emission contributors, and in defining a weightage to carbon capture and storage and net-negative emission technologies [24]. To add to this, with improved information, the carbon budget calculations have altered at times. A case in point is the carbon budget predictions in the Synthesis Report (SR15) published in 2018 [25] that have increased from that made in the Assessment Report (AR5) published in 2014 [9] by the IPCC. This has been attributed to a different temperature baseline, sophisticated modeling, and separation of Earth System feedbacks [26].

These variations sometimes make unanimous decision-making difficult but still provide a fair idea of the available global carbon left to expend. What stands out from these calculated values is that the time left is short (we need to reach net-zero by mid-century), the targets steep (since the available carbon budget is low), and the efforts limited. To stay within the available budget, two possible options exist. If we were to follow the global temperature restriction to $1.5^{\circ} \mathrm{C}$ as seen in [Figure 8], the mitigation strategy required would be extremely steep which can be achieved only through 'negative emission techniques' or by 'pulling out $\mathrm{CO}_{2}$ ' from the atmosphere. The second possible strategy is to follow the global temperature restriction of $2.0^{\circ} \mathrm{C}$ as seen in [Figure 9]. Both these strategies can be achieved by voluntary contributory efforts of the nations which are based on the Nationally Determined Contributions (NDCs), Intended Nationally Determined Contributions (INDCs), ${ }^{9}$ and Long-Term Strategies as submitted to the UNFCCC. However, since there is a definite gap between the pledges and the actual policies on-ground, the Paris Agreement targets are not likely to be realized as can be seen in [Figure 10].

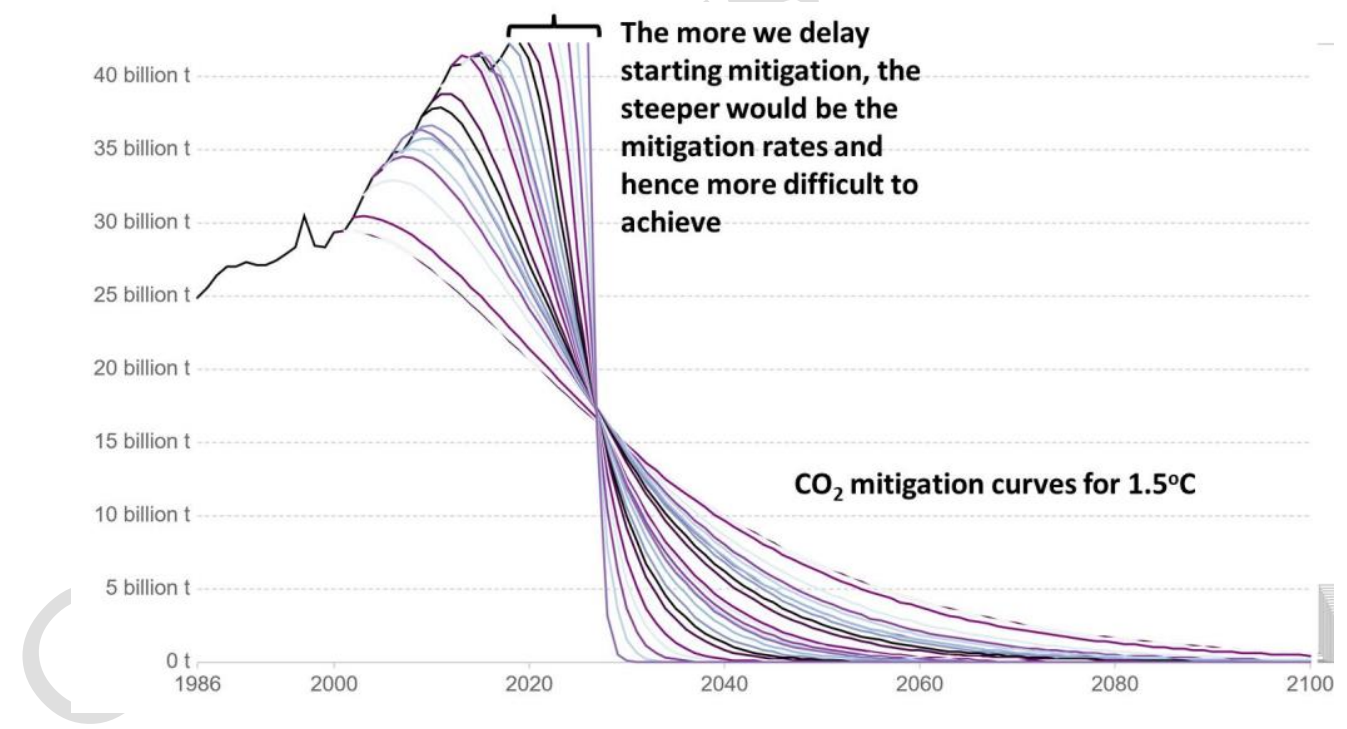

Figure 8. Options available to achieve the carbon budget with the global temperature increase restricted to $1.5^{\circ} \mathrm{C}$, adapted from [27]

\footnotetext{
${ }^{8}$ Warming is associated with the doubling of the GHG concentration.

${ }^{9}$ INDCs become NDCs when a country ratified the Paris Agreement.
} 


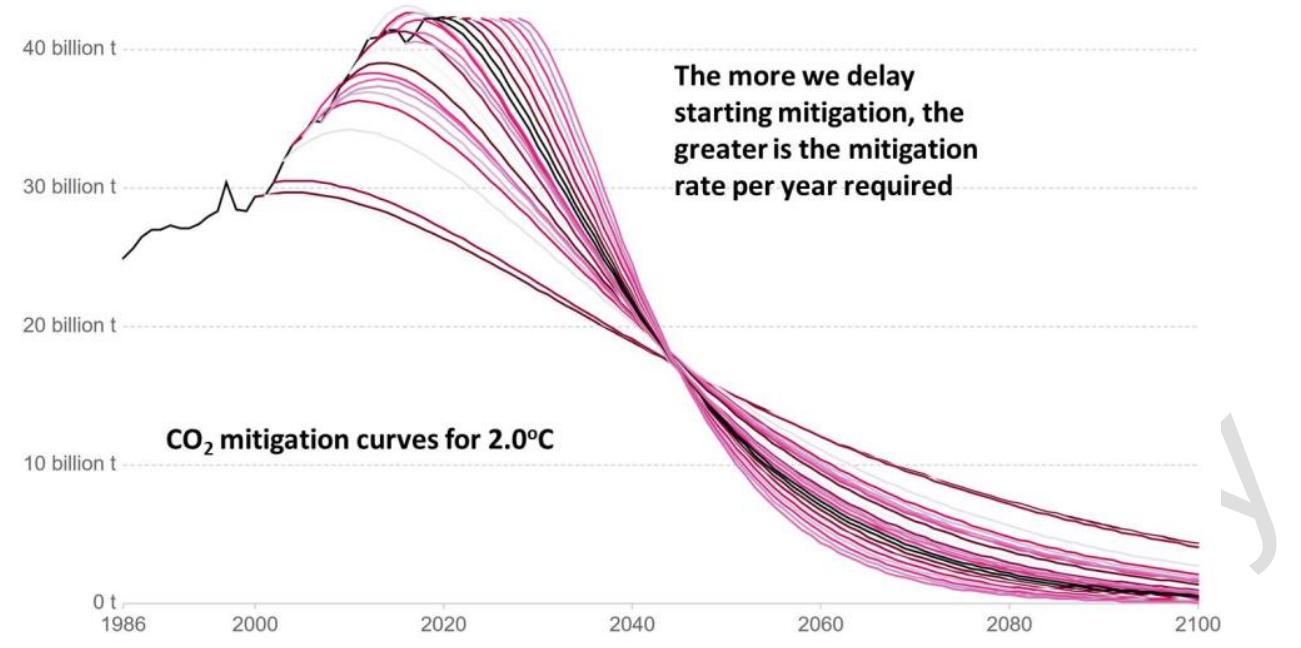

Figure 9. Options available to achieve the carbon budget the global temperature increase restricted to $2.0^{\circ} \mathrm{C}$, adapted from [27]

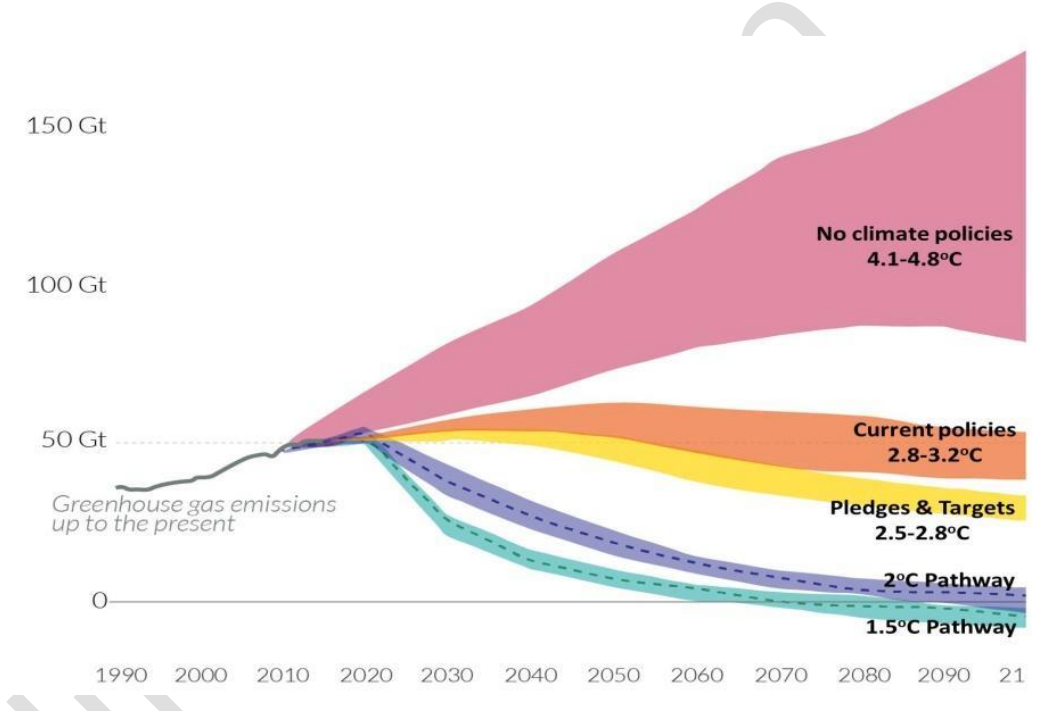

Figure 10. Targets of carbon budget, adapted from [27]

\subsection{Contributors to anthropogenic $\mathrm{CO}_{2}$}

As discussed in section 3.1, the GHG contains $\mathrm{CO}_{2}, \mathrm{CH}_{4}, \mathrm{~N}_{2} \mathrm{O}$, and Fluorinated gases. Of these, the anthropogenic contributors for each of these gases are shown in [Figure 11]. Since the contribution of anthropogenic $\mathrm{CO}_{2}$ is the maximum, we need to monitor the $\mathrm{CO}_{2}$ being produced. Based on the carbon cycle, the anthropogenic $\mathrm{CO}_{2}$ is calculated and monitored by breaking its contribution into five major components. These include the Fossil $\mathrm{CO}_{2}$ emissions (EFF) (from energy and cement production), land-use change (ELUC) (from deforestation), atmospheric $\mathrm{CO}_{2}$ (GATM) (from the annual changes in concentration), ocean $\mathrm{CO}_{2}$ sink (SOCEAN), and terrestrial $\mathrm{CO}_{2} \operatorname{sink}$ (SLAND). This measure gives us an idea of the result of the global efforts towards addressing reduction in anthropogenic $\mathrm{CO}_{2}$ emissions [28]. The resultant measurement provides us the broad breakup of the sector-wise contribution of the anthropogenic $\mathrm{CO}_{2}$ emission as seen in [Figure 12]. 
Curtailing Anthropogenic Carbon Dioxide to Meet the Targets of the Paris Agreement using Technology Support Mechanisms

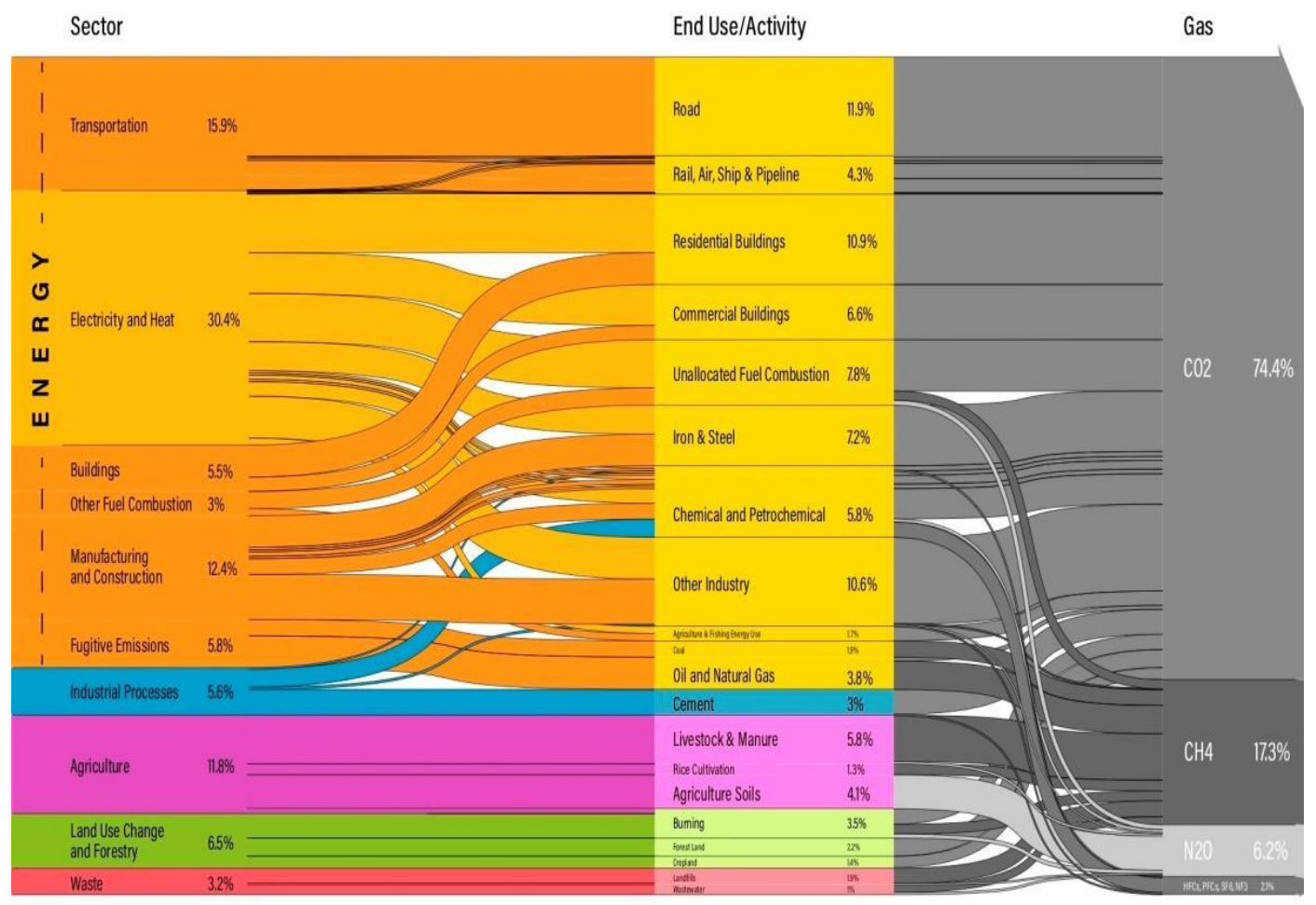

Figure 11. World GHG emissions in 2016 [29]

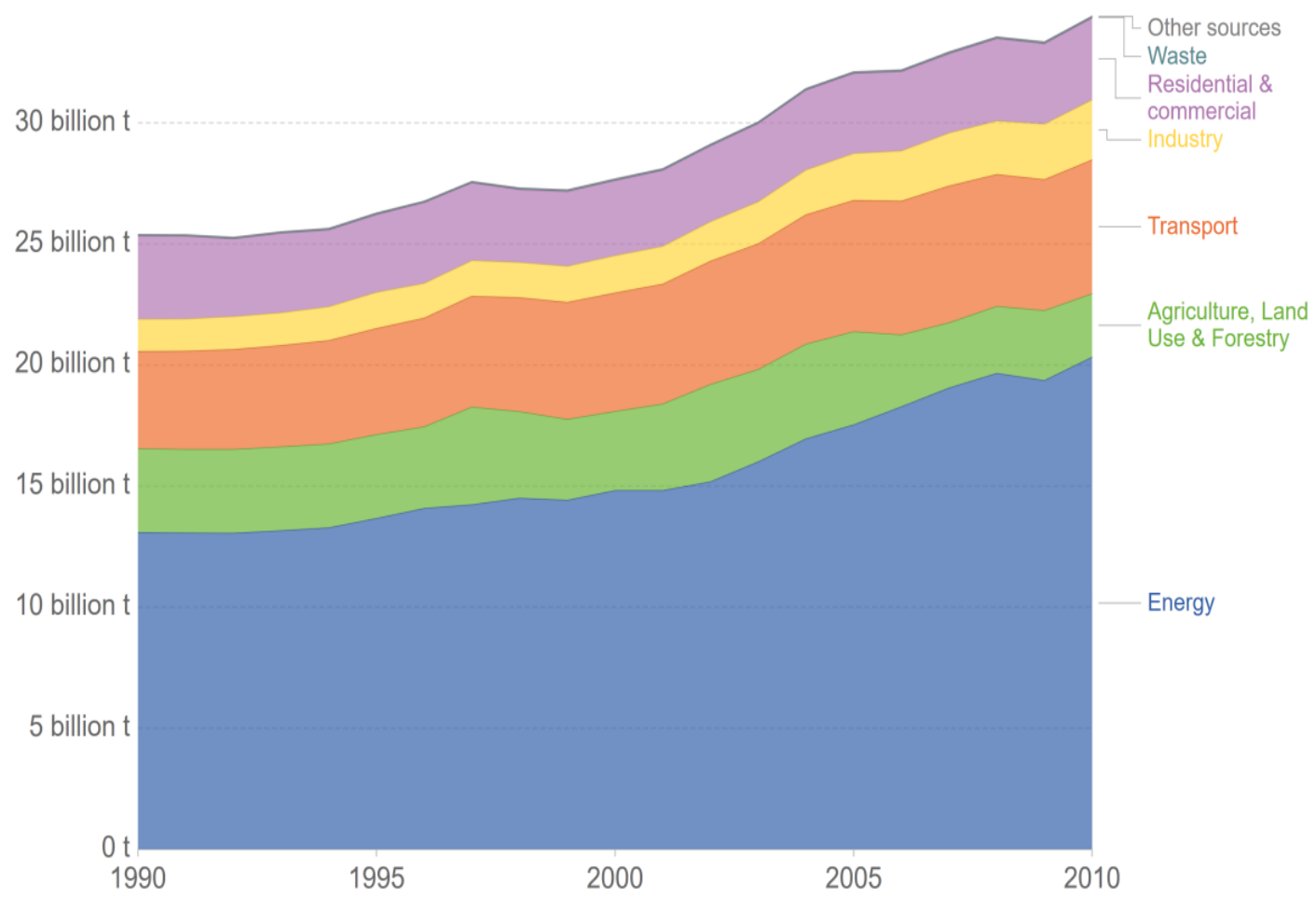

Figure 12. Sector-wise contribution of $\mathrm{CO}_{2}$ emissions [27] 


\section{Resolving climate change}

As seen in [Figure 12], the major contributors to anthropogenic $\mathrm{CO}_{2}$ emission are 'Energy' and 'Transport'. If the $\mathrm{CO}_{2}$ emissions are reduced from these two sectors, as has been observed in the first quarter of 2020 due to the forced confinements due to COVID-19 [10], a substantial reduction in the overall $\mathrm{CO}_{2}$ emissions can be achieved. In general, the emissions due to Energy constitute those from energy, manufacturing, construction industries, public heat, electricity production, and fugitive emissions from solid fuels, oil and gas, manufacturing industries, and construction as documented by IPCC AR5 and is seen in [Figure 13]. Controlling these contributors would help control the anthropogenic contribution of $\mathrm{CO}_{2}$. Similarly, the Transport sector includes domestic aviation, road transportation, rail transportation, domestic navigation, and other means of transportation as documented by IPCC AR5 [9] and is seen in [Figure 14]. Controlling these sectors would help achieve the required goal of $\mathrm{CO}_{2}$ reduction.

Over the years, each of these sectors has been studied independently by numerous researchers and have been documented extensively along with their mitigation methods in the various 'Assessment Reports: Mitigation of Climate Change' of the IPCC [5][6][7][8][9] and repeating them here is considered to be beyond the scope of this article.

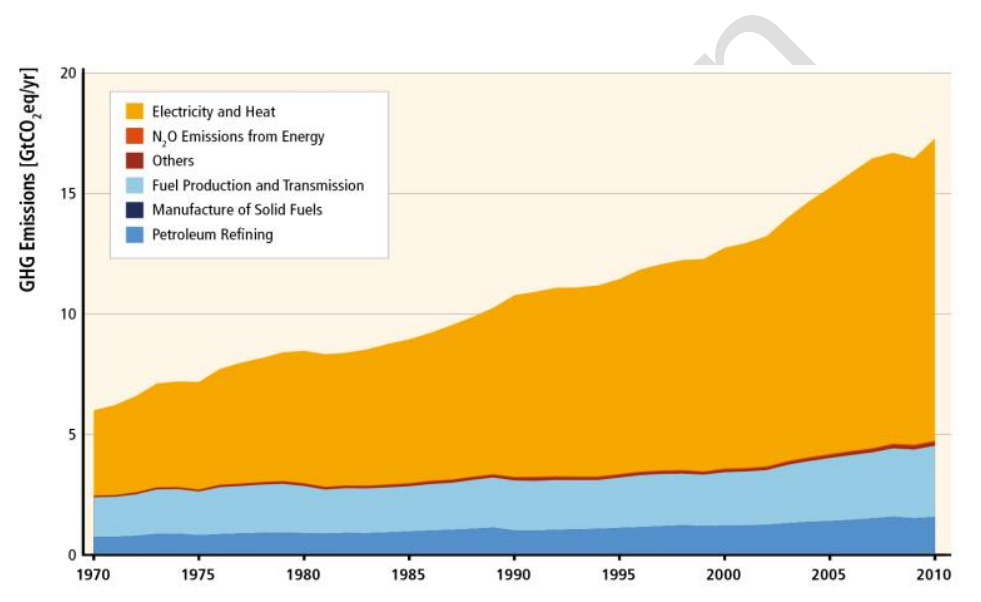

Figure 13. Direct GHG emissions from the energy sector [9]

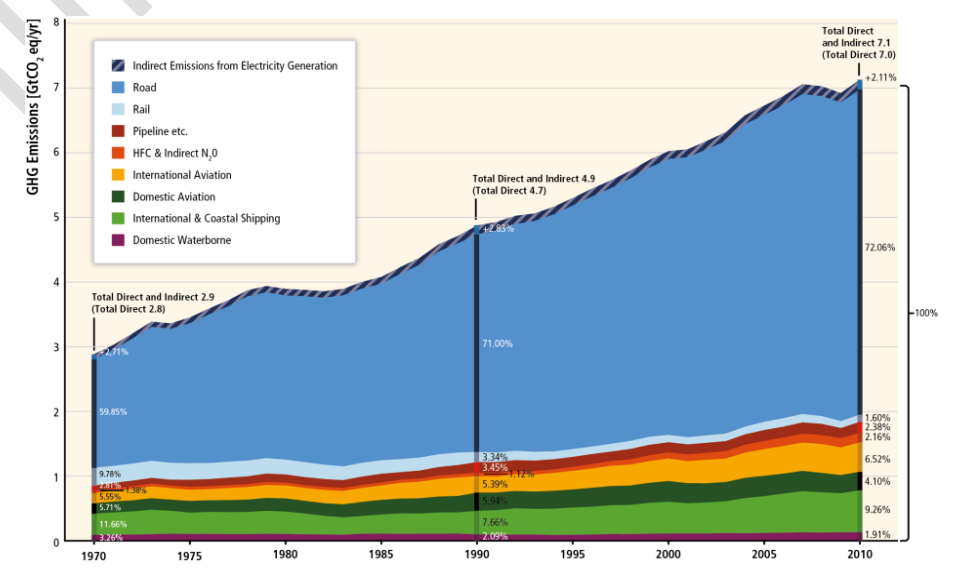

Figure 14: Direct GHG emissions from the transport sector [9] 
These IPCC reports and various other studies have shown that to meet the targets of the Paris Agreement, a shift to the new and alternate technologies is essential. This shift will be possible only at a very high cost, with higher climate risk, and under exceedingly optimistic assumptions about the success of future technologies [30]. However, it is never too late to make an honest and all-out attempt. The observed reductions of nearly 17 percent in emissions are an indicator of this possible success [10][31][32] as seen in [Figure 15]. Similarly, the reduction in electricity demand during the partial and the complete lockdown as recorded by the IEA as seen in [Figure 16] [33] can be correlated to the reduced $\mathrm{NO}_{2}$ emissions from the Vindhyachal Super Thermal Power Plant in India as seen in [Figure 17] as captured by ESA's Copernicus Sentinel$5 \mathrm{P}[31]$.

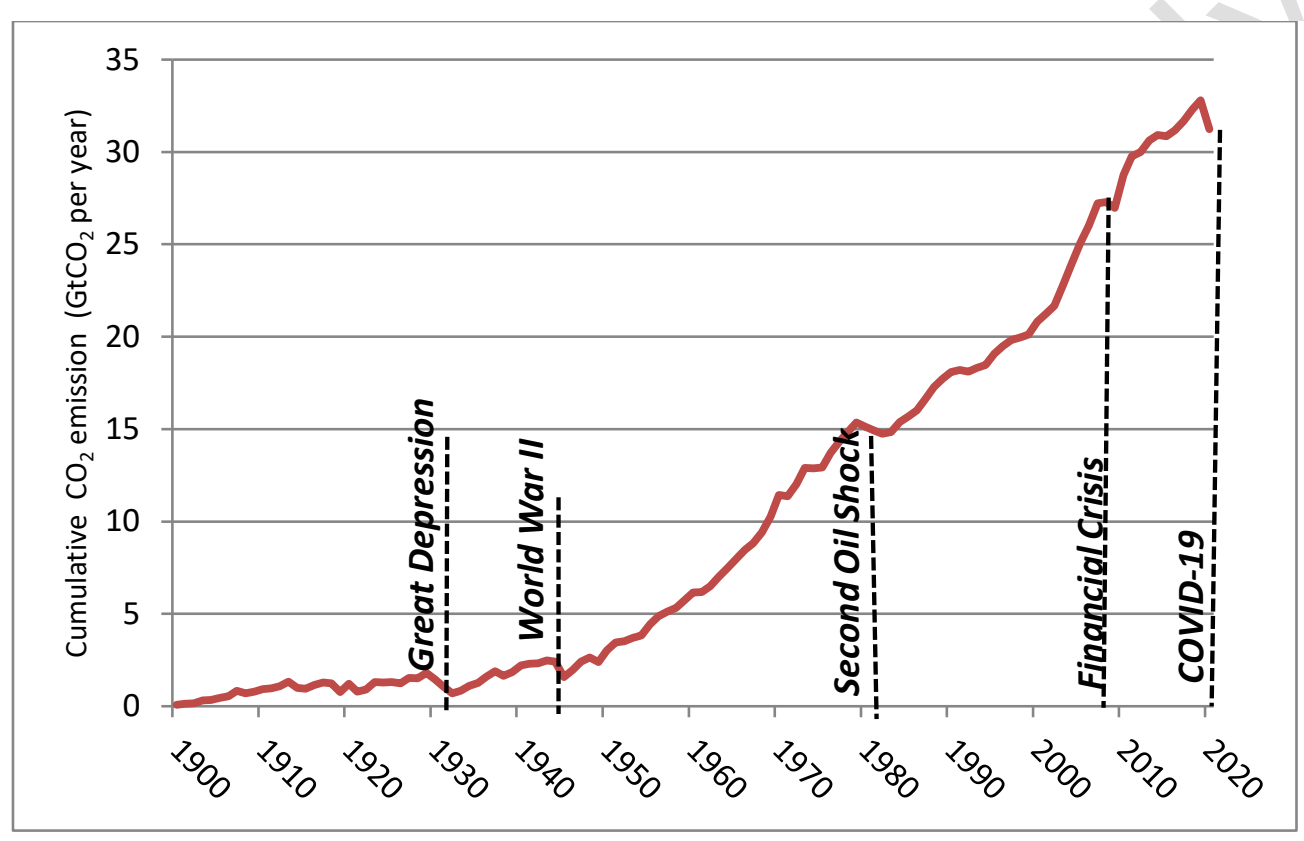

Figure 15. Reduction in GHG emissions due to forced confinement - Q1 of 2020, after [10]

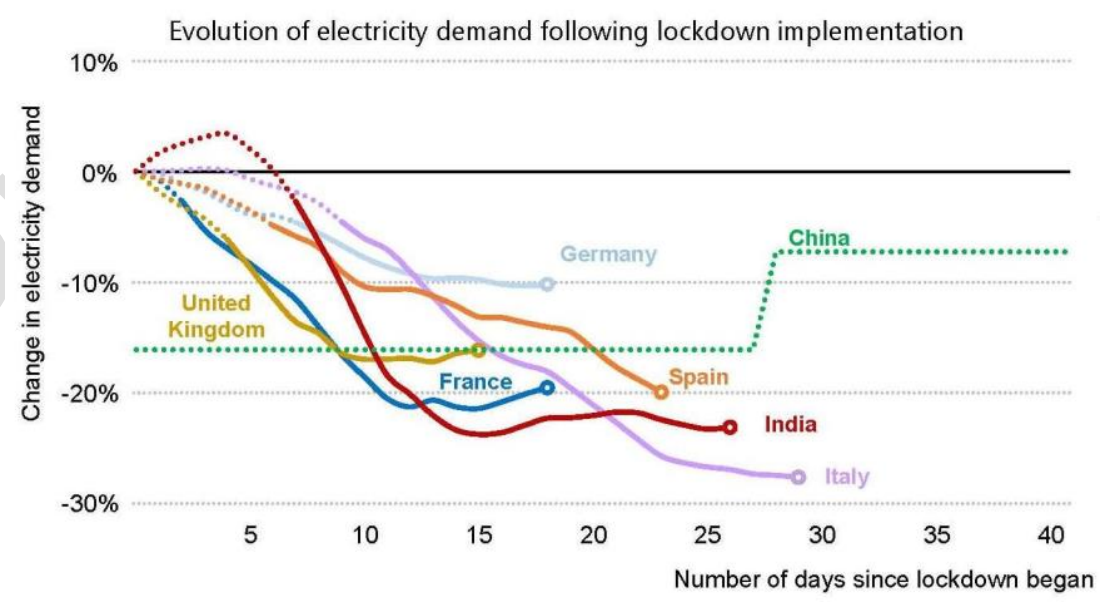

Figure 16. Reduction in electricity demand due to forced confinement - Q1 of 2020 [33] 


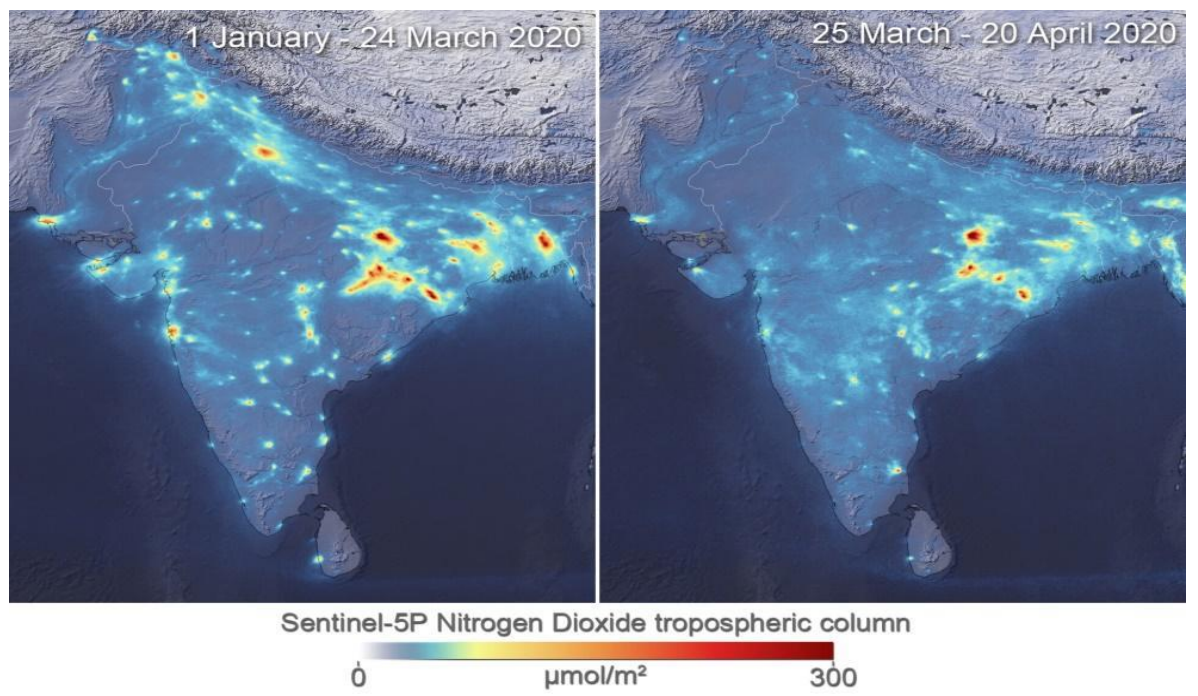

Figure 17. Reduction in $\mathrm{NO}_{2}$ emissions over India due to forced confinement - Q1 of 2020 [31]

Though this reduction is considered unsustainable due to the associated social trauma of forced confinement and the economic recession created by the pandemic, the authors believe that a sustained effort by all stakeholders can certainly go a long way in addressing the issue of $\mathrm{CO}_{2}$ emission reduction as required by the Paris Agreement. This is possible only if alternate technologies are used and the present obsolete and polluting ones are placed out of service.

\subsection{Technological imperatives to address $\mathrm{CO}_{2}$ emissions}

To achieve the desired goal of $\mathrm{CO}_{2}$ emission reduction, technologies using fossil fuel must be phased out completely and replaced with renewable, clean, and green energy. This is in line with the Long-Term Global Goals (LTGG) to reduce GHG emissions of the UNFCC. To achieve this, the use of technology is considered a way ahead. This has led to future technological R\&D focusing on areas of mitigation and adaptation, low-carbon investment, and green information and communication technologies. Such R\&D will help achieve, the less than $2^{\circ} \mathrm{C}$ global temperature target as adopted by the Paris Agreement, and is considered crucial for addressing climate change. While many challenges exist in system design and international cooperation, huge progress has already been made in technology development [34]. By and large, the experts of the IPCC, IEA, and UNEP agree that humanity has most of the essential technologies to address this issue, but lacks their deployment due to social, political, and economic barriers [35].

Accordingly, the technological approaches available to humanity to address the reduction of anthropogenic $\mathrm{CO}_{2}$ emission in the field of Energy and Transportation have been discussed in detail in IPCC SR15, Chapter 4, Table 4.5 (Section 4.4 - Policy approaches for adaptation and mitigation, technology and finance) [25] while their readiness for mitigation is discussed in IPCC SR15, Chapter 4, Table 4.11 (Strengthening and implementing the global response) [25].

What emerges is that there is no doubt about the advancements made on the technological front to address the reduction of anthropogenic $\mathrm{CO}_{2}$ emissions that can reduce the energy intensity required for economic development. However, further development of technology and infrastructure rely mainly on policies that support the environment, provide finance and help 
build human capacity. Currently, it is a lack of social and political will that has hampered the progress and development of a united effort by stakeholders of the world to address the issue of anthropogenic $\mathrm{CO}_{2}$ emission reduction. While the various international forums have left the implementation details and decisions on the respective countries based on the carbon budget allocated to them, the NDCs have mostly been lacking in achieving the INDCs. While this is happening, there is no international pressure on the defaulting nations for adherence as nearly all nations are defaulters and hence incapable of pressurizing the other nation(s). One may argue that poor and developing countries need to focus on the social development of their people than the global issues of climate change, but these nations tend to forget the fundamental that if the world ceases to exist how will they exist.

\subsection{COVID-19 as an initiator}

The recent event of the pandemic and those that have happened earlier have been eyeopeners of sorts for humanity, however, humans as they are, with a short-lived and objectoriented memory, tend to forget the lessons learned from previous events thereby continuing with their business-as-usual approach. Recent studies [10] have shown that $\mathrm{CO}_{2}$ emissions can come down if restrictions are put on human activities such as transportation and energy usage. It is time to learn from these observations and take steps to ensure that efforts are taken to reduce $\mathrm{CO}_{2}$ emissions by the Paris Agreement. A complete shutdown may not be feasible and acceptable just to achieve $\mathrm{CO}_{2}$ emission reduction, as it would lead to economic disaster and loss of livelihood for many. However, a calculated recommencement of activities and phasing out offensive pollutants could be considered. If this reducing trend as displayed during the Q1 of 2020 is continued, realizing the unachievable $\mathrm{CO}_{2}$ reduction may become achievable (see Figure 5).

Humanity as a race is aware of the offending anthropogenic activities such as energy and transportation that are increasing $\mathrm{CO}_{2}$ emissions. It is time to take constructive steps to ensure that these activities are curtailed and brought to a standstill and the technological alternates available are implemented. There may be some resentment from naysayers who feel that the technologies under consideration have not matured for use, however, bold baby steps are essential to support and hasten the further development of these technologies. This is keeping in mind the ethos that 'necessity is the mother of invention'. Such an effort would further allow higher volumes of production, thereby reducing production cost and increasing accessibility on the lines of 'the more you produce the cheaper it gets'.

It is prudent to mention that today 42 percent of the world's coal power stations are unprofitable due to higher running costs than, building a renewable energy generating plant. It is estimated that by 2030 nearly 96 percent of these coal power plants would become uneconomical [36]. This essentially means that in these times of economic recession, it makes better economic sense to shut down coal plants and replace them with renewable energy plants, thereby ensuring that the presently offensive $\mathrm{CO}_{2}$ emissions can be taken care of. Though the target of countries like the US is to completely phase out coal plants by 2030, this could be hastened with the right support from the policy makers.

Like earlier health emergencies (Plague, Cholera, and Typhoid of the nineteenth century) that brought about sustainable reforms to the society and the living conditions, let COVID-19 be remembered as an event responsible to have brought sustainability to humanity. To bring about such a change, the developed nations would need to lead the way through public and private participation, investment, and commitment. 
Over the months, various funding agencies of the world community have pledged nearly US\$ 14.0 trillion from 01 January to 24 May 2020 alone to fight COVID-19 and to revive their economies [37]. The EU is the only one that has decided on a 'green' stimulus package and placed climate change at the heart of its economic recovery. It aims to decarbonize electricity and phase out petrol and diesel vehicles to eventually reduce carbon emissions to net-zero only by 2050 [38]. However, as agreed in the Paris Agreement the desired target year is that of 2030, and the pandemic COVID-19 has shown it is feasible to be achieved. If the world was to consider a mere one percent of this total funding to be set aside as a central fund aimed squarely and purely for the development of technology to address climate change, it would deliver some amazing results.

\section{Is humanity on the right track?}

Studies have shown that climate change will affect nearly all countries across the globe. Some countries will benefit from the change while others will suffer [9][39][40]. Of these, the most impacted ones will be the poor nations who do not have the requisite financial or technological resources to prevent, adapt or fight against the impacts of climate change and those that are geographically vulnerable. This essentially means that since the likely impact due to climate change primarily due to anthropogenic contributors will not be the same, it is unlikely that the adaptation efforts and response of various nations to climate change will be the same. Similarly, since social and technological development is different in different nations, expecting the same standard of response towards climate change is inappropriate. If this is so, it is natural to believe that the efforts being pledged at the IPCC may not be realistic and that sincere efforts by one nation to stem the tide may be brought to naught by another who has disregarded these efforts towards climate change.

It hence goes to say that a concerted effort by all nations, rich and poor, developing and developed needs to be made against the ills of climate change as only a combined effort is what can provide the desired results. The Earth's environment is closely knit and connected that if even one nation decides to falter or work differently, the efforts of the other nations would be negated. While the task at hand to have all nations think and work together is uphill, it is not unachievable.

This said it is essential to mention that it is not that nothing is being done by the nations. Studies [41] have shown that in 2015, the world was on a $3.6^{\circ} \mathrm{C}$ global warming track by 2100 . However, by adhering to the adopted policies, use of renewable energy, and reduced use of coal, the world in 2020 is on a path of $2.9^{\circ} \mathrm{C}$ global warming. This achievement is still far from the Paris Agreement target of limiting warming to $1.5^{\circ} \mathrm{C}$. Achieving this stiff target requires countries to achieve net-zero GHG emissions. The sooner this happens, the sooner would global temperatures stop rising.

While in 2015 only a few countries had a net-zero emission target, the number of nations with such a target has increased. Still, nearly 37 percent of the 127 countries do not have a netzero target and hence achieving the committed figure of $1.5^{\circ} \mathrm{C}$ remains far away. When one looks at the NDCs of various countries, it is seen that of the 127 nations only 48 have submitted new NDC targets. Of these, 10 nations have submitted stronger NDC targets while 10 nations have not increased their ambitions. The current NDCs of the 32 countries, usually tracked, can be broadly categorized [42] along with their policy actions [43] as seen in [Figure 18] and the commitment of the best three and the worst three [41] about achieving their NDCs is seen in [Figure 19]. 
Curtailing Anthropogenic Carbon Dioxide to Meet the Targets of the Paris Agreement using Technology Support Mechanisms

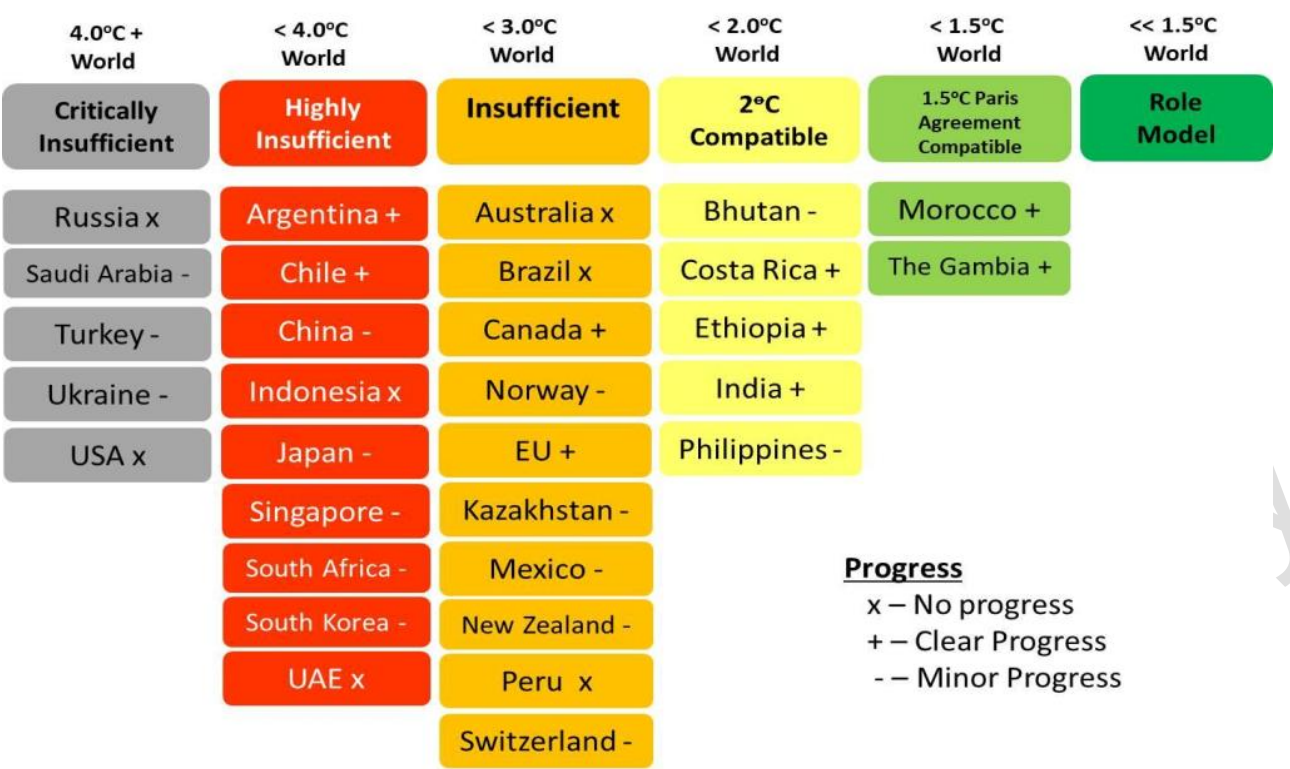

Figure 18: Status of NDCs of select countries with progress on NDC, after [42][43]

5 times emission goals

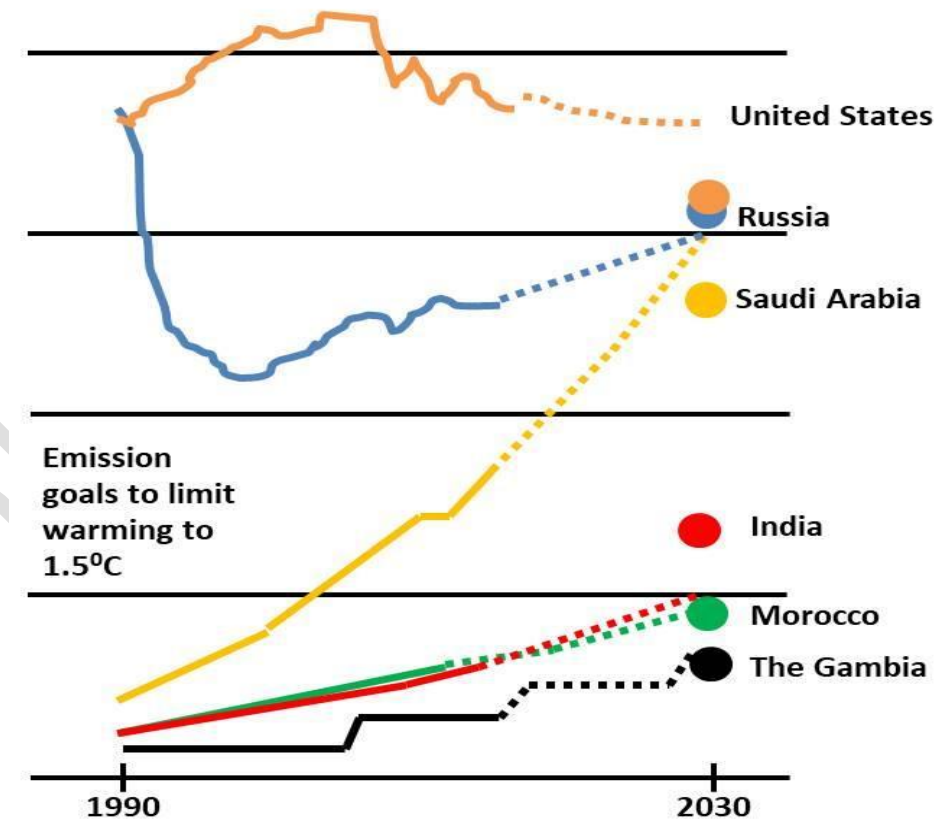

Figure 19. Countries achieving and missing set targets as in 2019 [44][45]

This discussion reflects that not every nation of the world is committed to the accepted targets of the Paris Agreement. This discussion also clearly brings out that though efforts to achieve $1.5^{\circ} \mathrm{C}$ targets through zero-emission targets are being pursued, it may fall short due to 
defaulting nations and since once nations have achieved zero-emission levels, no further efforts to achieve 'negative emissions' by 'pulling $\mathrm{CO}_{2}$ out of the atmosphere' are likely to be perused.

To achieve such a combined goal, some feasible technological support mechanisms are discussed herein. These support mechanisms are not considered conclusive, but provide a stimulus for a better and larger variety of solutions as technology is evolving and becoming smarter day by day.

\section{Recommended technology support mechanism}

To ensure that the various emerging technologies can help in reversing climate change and support environmental sustainability, both at the regional and the international level, these technologies need to be utilized by every country in the world to achieve maximum benefit. To be able to do so, some recommended support mechanisms that need to be put in place are:

- An institutional framework, at the global level, needs to be put in place to support the deliberations for sharing technology and funds to address $\mathrm{CO}_{2}$ emission mitigation. While there is no doubt that there would be resentment in sharing technology, especially when it has a dual-use capability, mechanisms need to be evolved to ensure that the sharing of technologies, in general, is done with due concern, caution, and consensus of the nation developing the technology. In the same breath, one needs to mention that adequate monetary compensation to the technology-developing nation needs to be factored in before sharing the technology.

- Emerging technologies need to be made available as global public goods to both the advanced and the developing countries alike [46]. Such a mechanism could be developed under the aegis of an international organization like the United Nations, ADB, ASEAN, or other regional cooperation mechanisms. Accordingly, the economically weak and underdeveloped nations would need to be provided with different types of support and commitment to adhere to the required standards of reducing $\mathrm{CO}_{2}$ emissions. Such an effort would help achieve greater participation and hence greater positive results.

- Ensure development, availability, and affordability of carbon-free technology and negative emission technology to meet the targets of the Paris Agreement in the available time. A possible model for implementing this could be using the innovation facility of the developed nations and the cheaper manufacturing capability of the developing nations, thereby creating a win-win solution for all.

- Undertake studies on environmental, social, and economic impacts of new and developing technologies in areas where they have not been evaluated to ensure acceptability of their usage. Such studies are considered critical since technologies such as 'negative emission' technologies are still to be commercialized due to lack of knowledge and our known dependence on conventional fossil fuel products.

- Create policy mixes to involve technology and society from both private and public to encourage new ideas. Such a mix can be successfully created by developing working paradigms of action and interconnection amongst technology, society, and the State.

- Technology and industrial policies at the national, regional, and global levels must be revised to address emission targets. Awareness must be spread to the ills of climate change to ensure that these policies are implemented successfully.

- Dedicated funds, akin to those committed to developing a cure for COVID-19, need to be pledged by the world community for the development and advancement of green technology to address emissions. It is imperative to mention that the world community 
has been slow to implement the targets of the Paris Agreement due to a lack of surplus funds, however, to address the pandemic, sufficient funds were available. By accepting that climate change is akin to a pandemic, such funds can be easily committed and the desired targets of the Paris Agreement met.

- The negative emission quota for each nation should be mandated [47]. Those unable to achieve it through their efforts should purchase it from countries capable of doing better (like a blood bank). Such an arrangement will encourage the development of negative emission technology while force defaulting nations to reduce emissions. Such a carbon bank needs to be controlled by an independent international organization to avoid corruption and ensure prompt and complete distribution of the collected funds.

- New technology must be introduced to replace old and obsolete technology rather than to augment resources. This is considered essential to ensure that the offending technology is removed quickly to minimize damage to the environment.

- In the name of business and philanthropy, obsolete technology should not be passed on to poorer nations. This would create unacceptable pollution levels at both the manufacturing (by manufacturing older technology through older and unsustainable methods) and the recipient nation (due to old technology). Herein again, mechanisms have to be created such that such transfers are avoided or if inevitable, be minimized.

- The combat against climate change needs a two-pronged approach to be successful. It needs to be top-driven (from the government to the citizens) and bottom to driven (with the citizens forcing the government) at the same time, however, without conflict. While the government can provide support of policy and funding for technological development [48], the citizens can ensure compliance and force the government to provide the necessary support. However, a detailed study in this regard needs to be commissioned especially in a diverse economic setup of the world community keeping in mind the interests and the economic status of the respective countries.

- With the development of the use of Artificial Intelligence to manage Marine Environmental Pollution [49][50], greater impetus needs to be given to such disruptive technologies to address climate change. It is finally such advanced and autonomous technologies that have the potential to address climate change.

\section{Conclusion}

Prolonged negligence and postponement of controlling and reducing anthropogenic $\mathrm{CO}_{2}$ emissions have made achieving the targets of the Paris Agreement in the desired time frame daunting. One needs to remember that there is no Planet ' $\mathrm{B}$ ' and time has come when a more than honest and concerted effort is required. The approach to success needs to be multipronged. Low-hanging initiatives such as the implementation of renewable energy and nuclear energy in place of coal and the use of Electric mobility in place of fossil fuel engines should be grabbed immediately. This needs to be supported with the developing new technologies and human behavioral change to support an efficient and low-energy lifestyle.

Since there is a vast divide between economic developments of nations, it is natural not to expect the same level of implementation of technology and behavioral change by all nations. While advanced nations may implement technological changes with ease, behavioral change will remain to be a key to the sustained achievement of the desired goals. For humanity to succeed, the developing nations need to succeed too. For this to happen, the advanced nations will need to give a helping hand for technology with behavioral change being addressed by the local governments themselves. 
One needs to remember that climate change and its effects will not differentiate between the developed and the developing as seen in the pandemic COVID-19. The war is against a common enemy, anthropogenic $\mathrm{CO}_{2}$ emission. If one nation fails the world fails.

While humanity continues to struggle with developing technology to reduce $\mathrm{CO}_{2}$ emission, the natural climate solutions such as conservation, restoration, and improved land management actions that increase carbon storage and/or avoid greenhouse gas emissions across global forests, wetlands, grasslands, and agricultural lands as recommended by IPCC should not be overlooked and be perused with equal rigor as suggested in chapter 4 of IPCC SR15.

\section{Abbreviations (Nomenclature)}

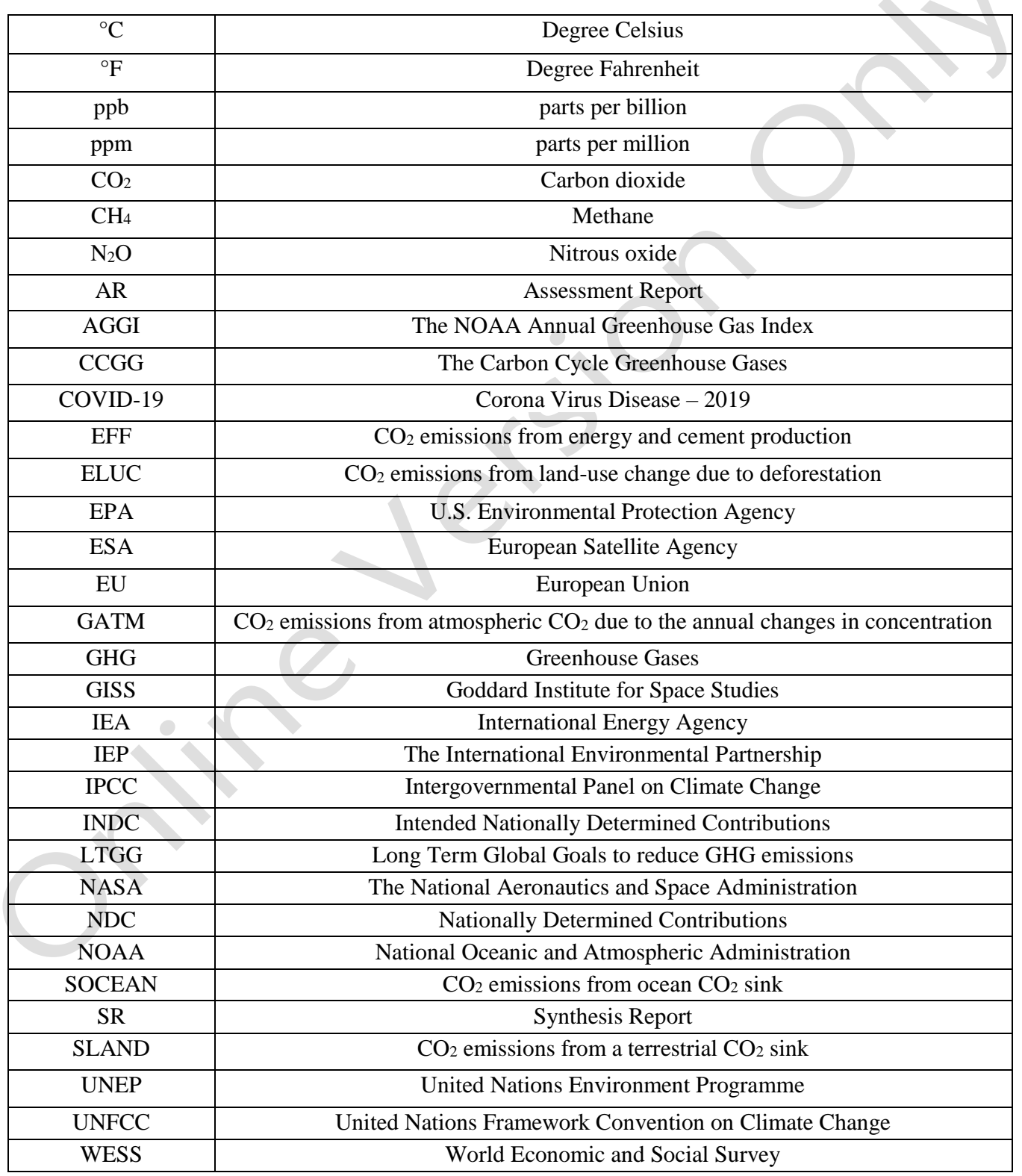




\section{References}

[1] Fourier, J. B., "On the temperatures of the terrestrial sphere and interplanetary space," Mémoires de L'Académie Royale des Sciences, 7, pp.569-603, (1827)

[2] Tyndall, J., "On the absorption and radiation of heat by gases and vapors, and the physical connexon of radiation, absorption, and conduction," Philosophical Magazine, vol.4, no.33, pp.169-194, 273-285, (1861)

[3] Fergus, Glen, “All palaeotemps”, Wikimedia Commons, (2014)

[4] Physical Geography.net, "Atmospheric Composition," Retrieved from 'http://www.physicalgeography.net/fundamentals/7a.html' [Online Resource]

[5] Intergovernmental Panel on Climate Change (IPCC), "FAR climate change: Scientific assessment of climate change," (1990)

[6] Intergovernmental Panel on Climate Change (IPCC), "SAR: The science of climate change," (1995)

[7] Intergovernmental Panel on Climate Change (IPCC), "TAR: Climate change 2001: The Scientific Basis," (2001)

[8] Intergovernmental Panel on Climate Change (IPCC), "AR4: Climate change 2007: The physical science basis," (2007)

[9] Intergovernmental Panel on Climate Change (IPCC), "AR5: Climate change 2014: Impacts, adaptation and vulnerability," (2014)

[10] Le Quéré, C., Jackson, R. B., Jones, M. W., et al., "Temporary reduction in daily global $\mathrm{CO}_{2}$ emissions during the COVID-19 forced confinement," Nature Climate Change 10, pp.647-653 (2020) DOI: 10.1038/s41558020-0797-x

[11] Liu, Z. Ciais, P., et al. "Near-real-time monitoring of global CO2 emissions reveals the effects of the COVID19 pandemic," Nature Communications, vol.11, no.1, (2020) DOI: 10.1038/s41467-020-18922-7

[12] Riebeek, H., “Global warming,” NASA, June 03, (2010)

[13] Jones, P. D., New, M., Parker, D. E., Martin, S. and Rigor, I.G., "Surface air temperature and its changes over the past 150 years," Reviews of Geophysics, vol.37, no.2, pp.173-199, (1999) DOI: 10.1029/1999RG900002

[14] EPA (U.S. Environmental Protection Agency), "Climate change indicators in the United States," EPA 430-R16-004, (2016)

[15] Friedlingstein, Pierre., et al., "Global carbon budget 2019," Earth Syst. Sci. Data, vol.11, pp.1783-1838, (2019), DOI: $10.5194 /$ essd-11-1783-2019

[16] NOAA., "The NOAA annual greenhouse gas index (AGGI)," Global Monitoring Laboratory (Formerly known as Earth System Research Laboratory), (2020) Retrieved from 'https://www.esrl.noaa.gov/gmd/aggi/aggi.html' [Online Resource]

[17] Dlugokencky, E. and Tans, Pieter, published online at $N O A A / G M L$, Retrieved from 'https://www.esrl.noaa.gov/gmd/ccgg/trends/global.html' [Online Resource]

[18] Dlugokencky, E., published online at $N O A A / G M L$, Retrieved from 'www.esrl.noaa.gov/gmd/ccgg/trends_ch4/' [Online Resource]

[19] Dlugokencky, E., published online at $N O A A / G M L$ Retrieved from 'www.esrl.noaa.gov/gmd/ccgg/trends_n2o/' [Online Resource]

[20] Intergovernmental Panel on Climate Change (IPCC), “AR5: Climate change 2014: Mitigation of climate change," (2018)

[21] Efbrazil, "Global temperature and forces," Wikimedia Commons, February 22, (2020)

[22] GISS. (Goddard Institute for Space Studies), "New studies increase confidence in NASA's measure of earth's temperature", May 23, (2019)

[23] Candela, Josep, and Carlson, David, "The annual global carbon budget”, World Meteorological Organization, Bulletin, vol.66, no.1, (2017)

[24] Sussams, L., "Carbon budgets explained," February 06, published online at Carbon Tracker, Retrieved from 'https://carbontracker.org/carbon-budgets-explained/' [Online Resource], (2018)

[25] Intergovernmental Panel on Climate Change (IPCC), “Climate change 2014: Synthesis report”, (2018) 
[26] Dalman A., "Carbon budgets: Where are we now?" May 11, published online at Carbon Tacker Blogs, Retrieved from 'https://carbontracker.org/carbon-budgets-where-are-we-now/' [Online Resource], (2020)

[27] Ritchie H. and Roser M., " $\mathrm{CO}_{2}$ and greenhouse gas emissions," Published online at OurWorldInData.org. Retrieved from: 'https://ourworldindata.org/co2-and-other-greenhouse-gas-emissions' [Online Resource], (2017)

[28] Le Quéré, C., Andrew, R., et al., “Global carbon budget 2018,” Earth Syst. Sci. Data, 10, 2141-2194, (2018) DOI: 10.5194/essd-10-2141-2018

[29] Ge, Mengpin, and Friedrich, Johannes, "4 charts explain greenhouse gas emissions by countries and sectors," World Research Institute, February 06, (2020)

[30] Rogelj, J., McCollum, D., O’Neill, B., et al., "2020 emissions levels required to limit warming to below $2{ }^{\circ} \mathrm{C}$," Nature Climate Change, vol.3, pp.405-412, (2013), DOI: 10.1038/nclimate1758

[31] ESA, “Air pollution drops in India following lockdown,” April 24, (2020)

[32] NASA, Earth Observatory, “Airborne particle levels plummet in Northern India,” April 21, (2020)

[33] IEA, "The impacts of the COVID-19 crisis on global energy demand and $\mathrm{CO}_{2}$ emission", Global Energy Review, April 30, (2020)

[34] Gao, Y., Gao, X., and Zhang. X., "The $2{ }^{\circ} \mathrm{C}$ global temperature target and the evolution of the long-term goal of addressing climate change - from the United Nations framework convention on climate change to the Paris agreement," Engineering, vol.3, pp.272-278, (2017) DOI: 10.1016/J.ENG.2017.01.022

[35] UNFCC. "Report on the structured expert dialogue on the 2013-2015 review," FCCC/SB/2015/INF.1, May 04, (2015)

[36] Carbon Tracker, " $42 \%$ of global coal power plants run at a loss, finds world-first study," Climate Action Tracker, November 30, (2018)

[37] Cornis, L., “Interactive: Who's funding the COVID-19 response and what are the priorities?”, Devex, May 28, (2020)

[38] Rowlatt, J., "Climate Change: How a green new deal could go global”, BBC, May 31, (2020)

[39] EPA (U.S. Environmental Protection Agency), "Climate change impacts: International climate impacts," January, (2017)

[40] Kompas, T., Pham, V. H. and Che, T. N. "The effects of climate change on GDP by country and the global economic gains from complying with the Paris climate accord," Earth's Future, vol.6, no.8, pp.1153-1173 (2018) DOI: $10.1029 / 2018 \mathrm{EF} 000922$

[41] CAT, "Paris agreement turning point," Climate Action Tracker, December, (2020)

[42] CAT, "Climate crisis demands more government action as emission rise," Climate Action Tracker, June, (2019)

[43] CAT, "Some progress since Paris, but not enough, as governments amble towards $3^{\circ} \mathrm{C}$ of warming," Climate Action Tracker, December, (2018)

[44] Le Quéré, C., et al., "Drivers of declining CO2 emissions in 18 developed economies," Nature Climate Change, vol.9, pp.213-217, (2019) DOI: 10.1038/s41558-019-0419-7

[45] Mulvaney, Kieran, "Climate change report card: These countries are reaching targets," National Geographic, September 19, (2019)

[46] WESS. "Frontier technologies for sustainable development," United Nations World Economic and Social Survey 2018, E/2018/50/Rev.1S T/ESA /370. Sales No. E.18.II.C.1, (2018)

[47] Pozo, C., Galán-Martín, Á., Reiner, D.M. et al., "Equity in allocating carbon dioxide removal quotas," Nature Climate Change, vol.10, pp.640-646, (2020) DOI: 10.1038/s41558-020-0802-4

[48] Agarwala, N., "Role of a policy framework for disruptive technologies in the maritime domain," Australian Journal of Maritime and Ocean Affairs, (2021) DOI: 10.1080/18366503.2021.1904602

[49] Agarwala, N., "Blue economy, plastic and marine pollution," Marine Engineers Review (India), vol.34, no.12, November, (2020) ISSN 2250-1967

[50] Agarwala, N., "Managing marine environmental pollution using artificial intelligence", Maritime Technology and Research, vol.3, no.2, pp.120-136, (2021) DOI:10.33175/mtr.2021.248053 


\section{Authors}

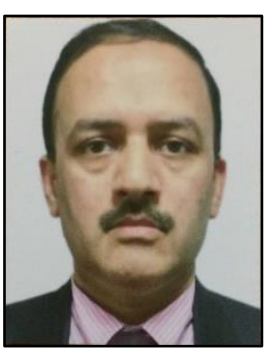

\section{Nitin Agarwala}

Nitin Agarwala is a serving naval officer who has experienced various facets of a warship as a user, designer, inspector, maintainer, policymaker, teacher, and researcher. He has authored over 70 articles, papers, book chapters, and two books entitled "Deep Seabed Mining in the Indian Ocean: Economic and Strategic Dimensions" and "Rise of China as a World Leader in Commercial Shipbuilding". His research interests include Corrosion, Shipbuilding, Deep Seabed Natural Resource, Submarine Cables, Blue Economy, Artificial Intelligence, Climate Change, and 'Maritime technological issues' with their linkages to International Relations and Public Policy. He can be contacted at nitindu@yahoo.com

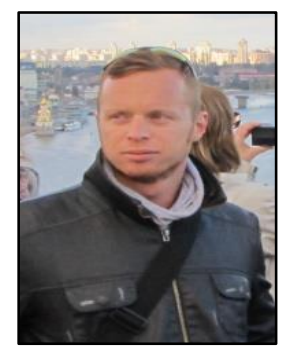

\section{Semion Polinov}

Semion Polinov is a Ph.D. candidate at the Dr. Moses Strauss Department of Marine Geosciences, the University of Haifa since 2017. His Ph.D. work deals with "Historical changes in human activities in the Mediterranean Sea and their drivers", under the supervision of Dr. Revital Bookman and Prof. Noam Levin. In 2019, he joined as a Research Associate in Maritime Policy and Strategy Research Center (HMS) where he works on the Geostrategic effects of climate change on Israel. Also, he is a course lecturer at the Dr. Moses Strauss Department of Marine Geosciences for "Practical GIS for Marine Geoscience" since 2018. His field of interest in GIS, Remote Sensing, and environmental analysis using Big Data. 